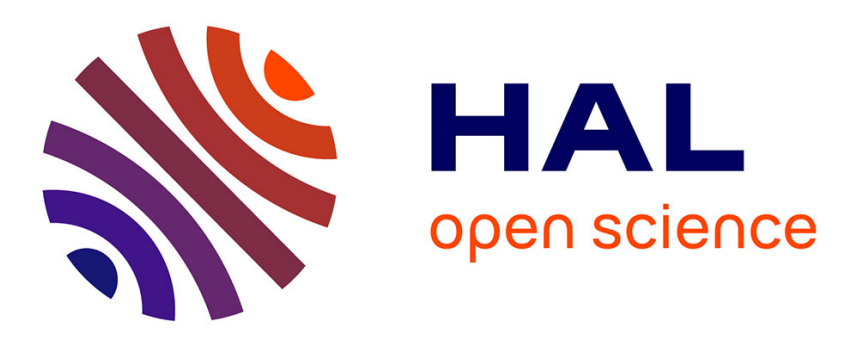

\title{
Photo-assisted electrodeposition of an electrochemically active polypyrrole layer on anatase type titanium dioxide nanotube arrays
}

Edgard Ngaboyamahina, Hubert Cachet, Alain Pailleret, Eliane Sutter

\section{- To cite this version:}

Edgard Ngaboyamahina, Hubert Cachet, Alain Pailleret, Eliane Sutter. Photo-assisted electrodeposition of an electrochemically active polypyrrole layer on anatase type titanium dioxide nanotube arrays. Electrochimica Acta, 2014, 129, pp.211-221. 10.1016/j.electacta.2014.02.106 . hal-01015454

\section{HAL Id: hal-01015454 https://hal.sorbonne-universite.fr/hal-01015454}

Submitted on 29 Jul 2014

HAL is a multi-disciplinary open access archive for the deposit and dissemination of scientific research documents, whether they are published or not. The documents may come from teaching and research institutions in France or abroad, or from public or private research centers.
L'archive ouverte pluridisciplinaire HAL, est destinée au dépôt et à la diffusion de documents scientifiques de niveau recherche, publiés ou non, émanant des établissements d'enseignement et de recherche français ou étrangers, des laboratoires publics ou privés. 


\title{
Photo-assisted electrodeposition of an electrochemically active
}

\section{polypyrrole layer on anatase type titanium dioxide nanotube}

\author{
arrays
}

\author{
E. Ngaboyamahina $^{\mathrm{a}, \mathrm{b}}$, H. Cachet $^{\mathrm{a}, \mathrm{b}}$, A. Pailleret ${ }^{\mathrm{a}, \mathrm{b}}$, E.M.M. Sutter ${ }^{\mathrm{a}, \mathrm{b}^{*}}$ \\ a- CNRS, UMR 8235, Laboratoire Interfaces et Systèmes Electrochimiques, 4, place Jussieu, \\ F-75005, Paris, France \\ b- Sorbonne Universités, UPMC Univ Paris 06, UMR 8235, LISE, 4, place Jussieu, F-75005, \\ Paris, France
}

\begin{abstract}
Our purpose is here to produce a large area $3 \mathrm{D}$ junction between anatase type $\mathrm{TiO}_{2}$ and polypyrrole (PPy) in a $\mathrm{Ti} / \mathrm{TiO}_{2}$ nanotube array (NTA)/PPy assembly with the help of electrochemical methods only. We report herein the influence of light and background salt on the electrochemical polymerization of pyrrole from aqueous electrolytic solutions on titanium oxide NTAs, a well-known large specific area n-type semiconductor substrate. As titanium dioxide is known to be poorly conducting in the anodic potential range, we confirmed that light is able to initiate a polymerization process of pyrrole, at a moderately high anodic potential. For comparison with results obtained in sodium dodecylbenzenesulfonate (SDBS) at micellar concentration, we used here also lithium perchlorate as background salt at a $0.1 \mathrm{M}$ concentration, and PPy growth was found to be faster in the presence of $\mathrm{LiClO}_{4}$. Moreover in the latter case polypyrrole could be initiated in the dark as well, yet at an enhanced deposition rate under UV light. In the two solutions. the resulting polypyrrole films were found to be
\end{abstract}

\footnotetext{
${ }^{*}$ Corresponding author :

Email : eliane.sutter@upmc.fr

Phone : +33(0) 144274168
} 
electroactive, i.e. able to undergo electrochemically driven doping/undoping processes, yet with a higher electroactivity for the film obtained in $\mathrm{LiClO}_{4}$. SEM-FEG and Raman spectroscopy experiments confirmed respectively that i) the initial steps of the photo-assisted electrodeposition of polypyrrole films occur first at the mouth of the titanium dioxide nanotubes, before leading to the well-known cauliflower-like morphology for PPy and ii) PPy is systematically produced in a doped state.

Keywords : $\mathrm{TiO}_{2}$ nanotube array, polypyrrole, impedance, photoelectropolymerisation 


\section{Introduction}

The study of semiconductor-electrolyte interfaces is of a great interest in research as a consequence of their numerous applications. The understanding of their behaviour has an impact on numerous technologies such as environment treatment (pollutant degradation), microelectronics, sensors, photocatalysis, photovoltaics, and energy storage for example. Among the most used semiconductors, $\mathrm{TiO}_{2}$ is well known for its low cost, chemical stability, and photoelectric conversion [1].

A way to improve metal oxide performances is to control their morphology at the nanoscale $[2,3]$. Precisely, the nanostructuration of $\mathrm{TiO}_{2}$ produced by anodization of a $\mathrm{Ti}$ foil enables to achieve highly ordered and vertically oriented nanotubular morphology. That leads to an increased specific area, direct transport pathways and the formation of a high density of surface states that influence the interfacial electron-transfer process [4].

Covering a nanostructured $\mathrm{TiO}_{2}$ interface with a conducting polymer film is expected to produce innovative $3 \mathrm{D}$ junctions possessing interesting photoelectrochemical characteristics and/or performances [5]. Among conducting polymers, polypyrrole (PPy) electrodeposition has been widely studied on usual electrode materials (platinum, gold, glassy carbon for example), thanks in part to its relatively easy electrosynthesis process and long term chemical and electrochemical stability [6,7]. During electropolymerization process, anions from the electrolyte [8] are incorporated in the polymer film to compensate the cationic charge resulting from the oxidation (i.e. doping) state of the growing conducting polymer film and are responsible for its ion exchange properties. It is well-known that the chemical composition of the electrolytic solution, and in particular, the type and size of the ions of the background salt present in the electrolyte are determining for the ion exchange 
behaviour of conducting polymers [9] and enable to control their electrochemical properties [10]. For instance, PPy films doped with large anions such as dodecylbenzenesulfonate (DBS) anions are expected to be mainly cation exchangers as a consequence of the irreversible entrapment of $\mathrm{DBS}^{-}$anions in the polymer matrix, unlike $\mathrm{PPy} / \mathrm{ClO}_{4}{ }^{-}$that are mainly anion exchanger films.

Attempts to electrodeposit polypyrrole on titanium oxide nanotube arrays have been recently described $[5,12-14]$. The challenge is to oxidize the pyrrole monomer in a potential range in which titanium dioxide, a n-type semiconductor, is depleted from majority carriers and only photooxidation is able to provide the holes necessary for electropolymerization. Another goal is to generate a doped and electroactive conducting polymer in tubes with a few tens of nanometers diameter. In the work published by Jin et al. [5], electropolymerisation was carried out under UV light (at $253.7 \mathrm{~nm}$ ) and was shown to lead to photoelectrochemically active $\mathrm{TiO}_{2}-\mathrm{NTA} / \mathrm{PPy}$ junctions resulting from the electrodeposition of PPy on the outer- and inner-walls of the NTs. In spite of these convincing observations, UV light was not always used in several other works published later on and sharing the same goal, i.e. electrodeposition of PPy on $\mathrm{TiO}_{2}$-NTAs $[11,13]$ which led incidentally or not in both studies to polypyrrole films whose electrochemical activity was not evidenced. On the other hand, localisation of polypyrrole electrodeposition was selected in a convincing and accurate manner by using SDBS at a micellar concentration as well as current pulses shown to favour diffusion of pyrrole into or between the $\mathrm{TiO}_{2}$ nanotubes depending on the inner diameter of the tubes and the void between them [11]. In some yet more recent contributions, beneficial effect of light on the electrodeposition process of electronically conducting polymers on metal oxide type semiconductors was thoroughly investigated and evidenced in the course of the photoelectrochemical polymerisation of PANI and PPy on nanoporous $\mathrm{WO}_{3}$, PANI on $\mathrm{TiO}_{2}$-NTAs [12]. Light was used by Janaky et al [14] for PPy deposition on 
$\mathrm{TiO}_{2}$-NTAs in a SDBS solution at micellar concentration. The authors clearly evidenced that polymerization was photoinitiated and that electropolymerization was likely to contribute to the overall polymerization reaction, once a seed layer of PPy was formed. The important result of their work was to show the higher electroactivity of the hybrid junction in comparison withan uncovered $\mathrm{TiO}_{2}$-NTA layer.

The present work aims at comparing pyrrole (Py) electropolymerization on a $\mathrm{TiO}_{2}$ nanotube array in two different solutions. A particular emphasis is placed i) on the role of UV light illumination during the electrochemical generation of PPy and ii) on the influence of the electrolyte anion. The deposition is performed by successive cyclic voltammetric scans. The characterization of the obtained composite structures is carried out by field emission gunscanning electron microscopy (FEG-SEM) and Raman spectroscopy so as to determine respectively the morphology and the oxidation state of the polymer deposit. Another important part of this contribution focuses on the analysis of electrochemical behaviour of the PPy films electrochemically grown on nanotubular $\mathrm{TiO}_{2}$ substrates as a function of the PPy electrodeposition parameters (light, background salt) using a potentiodynamic technique (Cyclic Voltammetry, CV) performed in the dark or under UV exposure, and electrochemical impedance spectroscopy (EIS).

\section{Experimental part}

\subsection{Synthesis of $\mathrm{TiO}_{2}$-NTAs}

Prior to anodic oxidation, titanium discs (thickness $2 \mathrm{~mm}$, diameter $15 \mathrm{~mm}$, purity $99.6 \%$, purchased from Goodfellow) were polished with silicon carbide abrasive paper (P1200), and then rinsed first with ethanol, and finally in water in an ultrasonic bath. Thereafter the Ti disc was anodized in a $3 \mathrm{wt} \% \mathrm{NH}_{4} \mathrm{~F}$ solution in ethylene glycol containing 2 vol\% deionised water using a large area platinum counter electrode in a two electrode setup. 
The oxidation was performed at room temperature $\left(21^{\circ} \mathrm{C}\right)$ under a constant potential of $20 \mathrm{~V}$ vs. Pt for $45 \mathrm{~min}$.

Once anodized, samples were ultrasonically rinsed in ethanol and deionised water successively. At last, they were annealed at $525{ }^{\circ} \mathrm{C}$ for $2 \mathrm{~h}$ so as to convert the amorphous $\mathrm{TiO}_{2}$ structure into a well crystallized anatase structure which has been thoroughly characterized [4]. Anodization of the $\mathrm{Ti}$ substrate led to dense and homogeneous $\mathrm{TiO}_{2}$ nanotube arrays (NTAs). Raman spectrometry and XRD spectrometry showed that anatase was the only component of the layer. The tubes exhibited smooth walls and were highlyordered and vertically oriented as it can be seen on the FEG-SEM pictures in Fig. 1. According to a geometric model previously used $[4,15,16]$ which considers a regular network of identical and equally spaced nanotubes, the developed surface of the whole nanotube arrays is given by the following equation:

$$
S_{t}=\frac{8 \pi h R_{2}}{\sqrt{3}\left(4 R_{2}-2 R_{1}+y\right)^{2}} \times S_{g e o}
$$

In our case, the flat surface of the samples (working electrode) exposed to the electrolyte, i.e. the geometric surface, $S_{\text {geo }}$, equals $0.78 \mathrm{~cm}^{2}$. In this equation, $\mathrm{R}_{1}$ and $\mathrm{R}_{2}$ are respectively the internal radius and the sum of $R_{1}$ and the half thickness of the wall of the nanotubes, whereas $\mathrm{y}$ is the thickness of the void between the tubes and $\mathrm{h}$ is the average length of these latter. That leads to a developed surface $\left(\mathrm{S}_{\mathrm{t}}\right)$ of approximately $50 \mathrm{~cm}^{2}$ for all the nanotube arrays produced and used throughout this work, taking into account the values of $21 \mathrm{~nm}, 26 \mathrm{~nm}, 13 \mathrm{~nm}$ and $960 \mathrm{~nm}$ for $\mathrm{R}_{1}, \mathrm{R}_{2}$, $\mathrm{y}$ and $\mathrm{h}$ respectively.

\subsection{Electropolymerization of Pyrrole}

Fresh aqueous solutions of $0.1 \mathrm{M}$ distilled pyrrole monomer were prepared in different 0.1 M supporting electrolytes, either sodium dodecylbenzenesulfonate (SDBS) or lithium 
perchlorate $\left(\mathrm{LiClO}_{4}\right)$. The resulting polymers are respectively named either PPy(DBS) or $\operatorname{PPy}\left(\mathrm{ClO}_{4}\right)$. In the case of SDBS, the selected concentration value is much higher than the value of critical micellar concentration, which has been shown to be about $1.5 \mathrm{mM}$ in aqueous solution [17]. Electropolymerization was carried out on a $\mathrm{TiO}_{2}-\mathrm{NTA}$ used as a working electrode by cyclic voltammetry between -0.7 and $1.0 \mathrm{~V}$ vs. SCE at a rate of $100 \mathrm{mV} / \mathrm{s}$ and at room temperature $\left(21^{\circ} \mathrm{C}\right)$.

For UV assisted photoelectropolymerization, the samples were illuminated with a 125 W mercury vapour lamp (HPR $125 \mathrm{~W}$ (Philips), wavelength range: 300-400 nm). The UV light source was placed at a distance of $25 \mathrm{~cm}$ from the working electrode and the UV beam was perpendicular to the working electrode surface.

$\mathrm{PPy}(\mathrm{DBS})$ and $\mathrm{PPy}\left(\mathrm{ClO}_{4}\right)$ thin films were also electrodeposited on Pt working electrodes $\left(\mathrm{S}_{\mathrm{geo}}=0.78 \mathrm{~cm}^{2}\right)$ and characterized for comparison.

\subsection{Characterization}

The morphology of the resulting $\mathrm{TiO}_{2}$ and polypyrrole samples was studied by FEGSEM (Zeiss, Ultra 55). A Jobin-Yvon (Labram 010) Raman spectrophotometer equipped with a He-Ne laser (wavelength $632.8 \mathrm{~nm}$ ) was used to confirm the structure of the polymer films as well as their oxidation state.

Electrochemical characterization of the obtained polymer films was performed in a three-electrode cell that was equipped when necessary with a UV source as described above. All the potentials are referred to a saturated calomel reference electrode (SCE). The counterelectrode was a platinum spiral wire.

An electrochemical interface (Solartron SI 1287) and a frequency response analyzer (Solartron 1250) were used to perform electrochemical impedance spectroscopy (EIS) measurements at a potential value selected inside a potential range situated between 0.5 and 1.1 V vs. SCE shown to encompass the oxidation/reduction (i.e. doping/undoping) of 
polypyrrole. A $0.1 \mathrm{~Hz}$ to $65 \mathrm{kHz}$ frequency range and a $10 \mathrm{mV}$ amplitude were applied during these EIS experiments. Experimental EIS spectra were fitted with ZSimpWin ${ }^{\mathrm{TM}}$ software (Princetown Applied Research).

\section{Results and discussion}

\subsection{Electropolymerization process}

\subsubsection{Preliminary experiments}

Before electropolymerization, preliminary experiments were performed to characterize the substrate in the absence of pyrrole in $0.1 \mathrm{M} \mathrm{SDBS}$ (or $\mathrm{LiClO}_{4}$ ) aqueous solutions. Fig. 2 shows the behaviour in $\mathrm{SDBS}$, but that observed in $\mathrm{LiClO}_{4}$ is very similar. In the dark, $\mathrm{TiO}_{2}$ NTA is charge-depleted in the potential range positive to $-0.6 \mathrm{~V}$ vs. SCE, whereas under UV illumination, a photocurrent is generated and first increases with increasing potential until it reaches a current plateau at $0.6 \mathrm{~V}$ vs. SCE. In the absence of any dissolved "oxidizable" species, this anodic photocurrent is due to water oxidation and is directly related to the exposed surface of the semiconductor.

\subsubsection{Electrodeposition of PPy(DBS) on $\mathrm{TiO}_{2}$-NTAs}

Fig. 3 shows the current response versus potential during electropolymerization attempts of pyrrole in a $\mathrm{TiO}_{2}$-NTA covered $\mathrm{Ti}$ substrate in the $-0.7 \mathrm{~V}$ to $1.0 \mathrm{~V}$ vs. $\mathrm{SCE}$ potential range. One can see the clear difference between the voltammogram obtained in the dark (see Fig. 3a) and that obtained under UV light illumination (Fig. 3b).

In the dark, during the 21 first scans the anodic current measured at $1.0 \mathrm{~V}$ vs. SCE is close to zero, similarly to the dark current usually observed with the substrate (Fig. 2), indicating that no electrochemical oxidation of the pyrrole monomer, and therefore no electropolymerization, occurs within this potential range. From the $22^{\text {nd }}$ scan, the anodic 
current starts slightly increasing, reaching only $40 \mu \mathrm{A}$ at $1 \mathrm{~V}$ vs. SCE after 40 scans. Nevertheless, the shape of the voltammogram does not show clearly any of the features expected for the voltammogram of the doping/undoping process of PPy films. Thus PPy electrodeposition appears to be unsuccessful in the dark in our experimental conditions in the presence of SDBS.

Under UV illumination, the behaviour is very different. During the first twelve scans, the anodic plateau reveals a photocurrent which decreases with time in the potential range from $0.0 \mathrm{~V}$ to $1.0 \mathrm{~V}$ vs. SCE, This is in close agreement with the observations made by Janáky et al. [14], who followed the evolution of the anodic current under illumination during the first five cycles in a similar potential range. Assuming that the anodic current was mainly a photocurrent with a possible contribution of electrooxidation, they attributed the anodic current decrease to $\mathrm{TiO}_{2}$ shielding by the growing polymer. In the present work, further scanning was performed and the results are the following:

The anodic current measured at $1.0 \mathrm{~V}$ vs. SCE decreases from the first up to the $12^{\text {th }}$ scan, as a result of the decrease of $\mathrm{TiO}_{2}$ surface exposed to light, during polymerization. This anodic response drops rapidly throughout the first 5 scans (from $290 \mu \mathrm{A}$ down to $185 \mu \mathrm{A}$ ) and then, the rate of decrease slows down. During the 12 first scans, this anodic current is assumed to be the sum of $\mathrm{TiO}_{2}$-NTA photocurrent on one hand and growing PPy doping/undoping and Py monomer oxidation on the other hand. Nevertheless ,according to [14], the former current is certainly the main contribution to the global anodic response hiding the latter one.

From the $13^{\text {th }}$ scan, a rise of the current is observed as a function of the applied potential, and the shape of the voltammogram looks closer to the classical one observed on a conducting substrate during the electrochemical deposition of polypyrrole [18, 19]. We must admit that the contribution of the photocurrent to the total current can now be neglected and 
that pyrrole oxidation and polypyrrole doping become the main contributions to the global anodic response in the 0.6 to $1.0 \mathrm{~V}$ vs. SCE and -0.4 to $0.6 \mathrm{~V}$ vs. SCE potential ranges respectively.

At $1 \mathrm{~V}$ vs. SCE after 40 scans, the anodic current reaches $1000 \mu \mathrm{A}$, which has to be compared to the $40 \mu \mathrm{A}$ reached on Fig. 3a in similar conditions without illumination. One can point out that the cathodic wave attributed to PPy undoping never stops increasing under illumination on Fig. 3b.

In close agreement with the conclusion in Ref [14], we must admit that the $\mathrm{PPy} / \mathrm{TiO}_{2}$ NTA junction shows higher electroactivity in a wide potential range, than uncovered $\mathrm{TiO}_{2-}$ NTA layers.

\subsubsection{Electrodeposition of $\mathrm{PPy}\left(\mathrm{ClO}_{4}\right)$ in $\mathrm{TiO}_{2}$-NTA}

For comparison, polypyrrole was also electrodeposited in the dark and under UV illumination in a $\mathrm{LiClO}_{4}$ aqueous electrolytic solution. Fig. 4a shows the cyclic voltammogram obtained in the dark during 40 scans. Anodic and cathodic currents measured respectively at $1 \mathrm{~V}$ and $-0.2 \mathrm{~V}$ vs. SCE rise endlessly in absolute values during consecutive CV scans. Fig. 4b represents the cyclic voltammogram obtained under UV light during electropolymerization in the presence of $\mathrm{LiClO}_{4}$. The behaviour is almost the same as that in the dark, with a clear nucleation loop appearing from the second scan. It must be noticed that the current response is twice higher in Fig. $4 \mathrm{~b}$ by comparison with Fig. 4a, showing a higher deposition rate under lighting. It is noticeable that no photocurrent plateau is observed, indicating that the oxidation of pyrrole and doping/undoping of polypyrrole are the main contributions to the anodic and cathodic currents from the first scan of polarization.

Compared to electropolymerization of pyrrole in SDBS, it appears that the rate of electropolymerization of $\mathrm{Py}$ in $\mathrm{LiClO}_{4}$ is much higher and the corresponding anodic current increases rapidly when the number of scans increases. This comparison shows that the rate of 
PPy deposition does not only depend on the amount of photogenerated holes created in $\mathrm{TiO}_{2}$ through UV excitation, but also depends on the background salt, possibly through the identity of anion and/or cation inserted during the electrochemically driven doping/undoping process and/or ion and monomer transport towards the electropolymerisation sites on/in the $\mathrm{TiO}_{2}$ NTA. This result will be discussed below.

In the cathodic potential range, the large cathodic current value measured at $-0.2 \mathrm{~V}$ vs. SCE due to PPy undoping increases continuously with the increase in the scan numbers, reaching much higher values in $\mathrm{LiClO}_{4}\left(\approx-1400 \mu \mathrm{A}\right.$ for the $40^{\text {th }}$ scan under UV light in Fig. 4b) than in SDBS (-300 $\mu$ A for the $40^{\text {th }}$ scan under UV light in Fig. 3b).

In the two electrolytes, the vanishing of the photocurrent after 40 cycles results from incident light absorption by the polypyrrole layer. Taking an absorption coefficient value of about $2.10^{5} \mathrm{~cm}^{-1}$, (value taken from ref [20]), we can estimate that a thickness of $50 \mathrm{~nm}$ for the polypyrrole layer is sufficient to completely absorb the incident light.

The main conclusion from the comparison between PPy formation in the two electrolytes is that light is necessary in SDBS for deposition of a polymer seed layer, whereas in $\mathrm{LiClO}_{4}$ polymerization already starts in the dark.

\subsection{Electrochemical characterization of deposited PPy film}

The electrochemical characterization was performed in the same supporting electrolyte as that used for the synthesis but without Py monomer. The aim of these experiments was i) to reveal the expected electroactivity of the polypyrrole films electrodeposited on $\mathrm{TiO}_{2}-\mathrm{NTA}$, and ii) to estimate the ratio between PPy covered and uncovered $\mathrm{TiO}_{2}$ areas, assuming that the dark anodic current is mainly due to PPy oxidation, whereas the photocurrent is related to uncovered $\mathrm{TiO}_{2}$ areas 


\subsubsection{PPy(DBS) in SDBS electrolyte}

PPy layers synthesized in SDBS using 40 consecutive cyclic voltammograms in the dark were characterized in the dark as well as under UV light. Fig. 5a shows that the behaviour is very similar to the behaviour of uncovered $\mathrm{TiO}_{2}$ (Fig. 2), with a dark current close to zero and a photocurrent of same amplitude as in the absence of PPy. This result confirms that PPy deposition was not initiated on $\mathrm{TiO}_{2}$-NTA in the dark, when SDBS was used as supporting electrolyte.

PPy layers obtained in SDBS under UV light were also characterized in the dark (Fig. 5b). During the scan towards more positive potentials, an oxidation peak observed at about $-0.2 \mathrm{~V}$ vs. SCE can be reasonably attributed to polymer oxidation (or doping). During the reverse scan a wide reduction peak with a maximum at $-0.7 \mathrm{~V}$ vs. SCE can be attributed to the electrochemical reduction of the doped polymer (undoping). During this reverse scan, one can predict that cations from the electrolyte, such as $\mathrm{Na}^{+}$and/or $\mathrm{H}^{+}$, are inserted in the polymeric layer to ensure electroneutrality, as a consequence of the irreversible entrapment of bulky dodecylbenzenesulfonate anions during the electrodeposition step of this polymer film. These peak attributions are confirmed by the voltammogram obtained on Pt (Fig. 5c) that shows very similar features to those observed in Fig. 5b. Nevertheless, as pointed out in [14], the distance between the anodic and cathodic peaks are higher than on Pt, indicating sluggishness of the redox reactions.

When the $\mathrm{Ti} / \mathrm{TiO}_{2}-\mathrm{NTA} / \mathrm{PPy}(\mathrm{DBS})$ sample was characterized under $\mathrm{UV}$, the anodic current clearly increased (Fig. 5b), indicating that a photocurrent contributes to the global current. Two hypotheses can be suggested: either the PPy layer is thinner than $50 \mathrm{~nm}$, or the deposit is heterogeneous and the surface of $\mathrm{TiO}_{2}$ is only partially covered by the polymer. Fig. 6a is a FEG-SEM picture of $\mathrm{TiO}_{2}-\mathrm{NTA} / \mathrm{PPy}$ synthesized under illumination in SDBS after 40 scans. In comparison with the bare $\mathrm{TiO}_{2}$ sample (Fig. 1 or inset in Fig. 6), expansion of the 
wall thickness and disappearance of nanoscopic voids between and inside the tubes can be observed. Nevertheless the deposit is non-uniform over the whole surface and some $\mathrm{TiO}_{2}$ tubes remain uncovered, which strengthen the second of our two hypotheses raised above.

Fig. $6 \mathrm{~b}$ is a side view of the polymeric deposit taken at the sample cracks, showing that polymerisation occurs along the whole length of the tubes.

In the dark and under UV, the cathodic currents due to PPy undoping are the same (Fig. 5b), given that PPy does not produce any photocurrent under UV. Moreover we do not expect any light induced contribution in this potential range from $\mathrm{TiO}_{2}$ which is a n-type semiconductor

The influence of the number of scans applied during electrodeposition of PPy film deposited in SDBS was investigated, assuming that the deposition is non uniform according to the FEG-SEM images (Fig. 6a). The dark anodic current measured between $-0.4 \mathrm{~V}$ and $1.0 \mathrm{~V}$ vs. SCE during the characterization is then mainly attributed to PPy oxidation, whereas the photocurrent measured in the same potential range under UV light is only related to uncovered $\mathrm{TiO}_{2}$ areas. The ratio between PPy covered and uncovered $\mathrm{TiO}_{2}$ areas was estimated for different PPy deposits resulting from different numbers of consecutive cyclic voltammetry scans, by comparing the dark current and the photocurrent of the composite structures to the photocurrent measured for uncovered pristine nanotubes. The measurements were performed for composite structures obtained after respectively 50, 70 and 100 scans. The percentage of uncovered nanotubes surface $\mathrm{S} \%$ is then given by the following relation:

$$
\mathrm{S} \%=\frac{I_{a}^{u v}-I_{a}^{\text {dark }}}{I_{a}^{u v}\left(\text { pristine } \mathrm{TiO}_{2}\right)} * 100
$$

From Table 1 , one can see that this percentage is almost the same $(\sim 25 \%)$ whatever the number of scans. This means that the surface coverage of $\mathrm{TiO}_{2}-\mathrm{NTA}$ by the polypyrrole does not increase anymore beyond the $50^{\text {th }}$ scan in spite of the increase in the current attributed to the doping/undoping of the growing polypyrrole film. It seems that beyond the 
$50^{\text {th }}$ scan, the polypyrrole growth implies a thickening of the film without any further spreading out on the $\mathrm{TiO}_{2}$ substrate, the $\mathrm{TiO}_{2} / \mathrm{PPy}$ junction providing a preferential path for electron transfer.

\subsection{2 $\mathrm{PPy}\left(\mathrm{ClO}_{4}\right)$ in $\mathrm{LiClO}_{4}$ electrolyte}

After synthesis of the organic polymer film in $\mathrm{TiO}_{2}-\mathrm{NTA}$ in $\mathrm{LiClO}_{4}$ aqueous electrolyte, the electrochemical activity of the composite structure was characterized in the same supporting electrolyte using cyclic voltammetry, firstly in the dark, then under UV light. When PPy was deposited in the dark in $\mathrm{LiClO}_{4}$ electrolyte (Fig. 4a), the cyclic voltammograms obtained after transfer in a blank electrolytic solution respectively in the dark and under UV light strongly differed (see Fig. 7a). It is interesting to notice that the CV obtained in the dark clearly shows the electroactivity of PPy, by the presence of an anodic peak at $0.2 \mathrm{~V}$ vs. SCE and a cathodic peak at $-0.15 \mathrm{~V}$ vs. SCE corresponding respectively to the electrochemically driven doping and undoping of polypyrrole. One can thus conclude that when the background salt chosen for the electrodeposition step is $\mathrm{LiClO}_{4}$, PPy can be electrochemically grown on a $\mathrm{TiO}_{2}$-NTA array in the absence of light. This is very different from SDBS solution, in which no PPy film was electrodeposited in the dark. The characterization of $\mathrm{PPy}\left(\mathrm{ClO}_{4}\right)$ currents under light exposure clearly shows the contribution of a photocurrent to the total anodic current (Fig. 7a). This result indicates either that the PPy layer is very thin $(<50 \mathrm{~nm})$ or that the coverage of the surface by PPy is non homogeneous. The FEG-SEM images (not shown) indicate the same mechanism of deposition as in Fig. 6a, with an enlargement of some of the tube walls and an overall heterogeneous deposition.

When PPy was previously deposited under UV light in $\mathrm{LiClO}_{4}$ electrolyte (Fig. 4b), a typical voltammogram corresponding to electrochemical doping/undoping of PPy was observed. Moreover, no difference was observed between the voltammogram obtained in the dark or under UV light (Fig. 7b). The absence of photocurrent indicates that the surface of 
$\mathrm{TiO}_{2}-\mathrm{NTA}$ is fully covered with an electrodeposited polypyrrole whose thickness is higher than $50 \mathrm{~nm}$. Accordingly, the corresponding FEG-SEM picture in Fig. 6c shows the wellknown cauliflower-like morphology over the whole surface of the $\mathrm{TiO}_{2}$-NTA.

At this stage, one can conclude that polypyrrole deposition on $\mathrm{TiO}_{2}$-NTA is easier (faster) in the presence of lithium perchlorate than in that of SDBS used as a supporting electrolyte. This observation confirms the detrimental character of SDBS in the efficiency of electrodeposition of polypyrrole on anatase type $\mathrm{TiO}_{2}$-NTAs from aqueous solutions. Nevertheless a higher deposition rate does not necessarily lead to a better coverage rate of the tube walls by the polymer, given the low rate of mass transport of the reactants which control the electrochemical process. Moreover direct comparison between the two media can hardly be performed, since in SDBS surfactant aqueous solution, the pyrrole monomer is likely to be included and therefore transported inside SDBS micelles, which is not the case in $\mathrm{LiClO}_{4}$. The efficiency of monomer supply is therefore expected to be very different in the two solutions.

For the need of comparison, polypyrrole films electrodeposited on platinum electrodes in similar conditions to those used in Fig. 4 were electrochemically characterized in $\mathrm{LiClO}_{4}$ electrolyte (Fig. 7c). In Fig. 7a, b and c, two cathodic peaks appear in the same potential range on the three CVs, namely at about $-0.85 \mathrm{~V}$ and $-0.15 \mathrm{~V}$ vs. SCE respectively, whereas the oxidation peak is slightly more positive on $\mathrm{TiO}_{2}-\mathrm{NTA} / \mathrm{PPy}\left(\mathrm{ClO}_{4}\right)$ compared to that observed on Pt-PPy $\left(\mathrm{ClO}_{4}\right)$ (at about $0.2 \mathrm{~V}$ vs. SCE in the former case and $0.1 \mathrm{~V}$ vs. SCE in the latter case). This slight difference can be attributed to a difference in conductivity between the two substrates, $\mathrm{TiO}_{2}$ being more resistive than $\mathrm{Pt}$. It is noticeable that the anodic currents measured in Fig. $7 b$ and $c$ are comparable, though the specific area of $\mathrm{TiO}_{2}-\mathrm{NTA}$ is close to $50 \mathrm{~cm}^{2}$ whereas that of platinum is about $0.78 \mathrm{~cm}^{2}$. The similarity between the current values in the two cases can be due to a lower thickness of the PPy film on $\mathrm{TiO}_{2}$-NTA in comparison 
with $\mathrm{Pt}$, or to the fact that the surface of $\mathrm{TiO}_{2}-\mathrm{NTA}$ covered by a PPy film is close to the geometric surface, and that deposition only occurred at the upper part of the tubes. The voltammogram corresponding to the electrochemical characterization of $\mathrm{PPy}\left(\mathrm{ClO}_{4}\right)$ in $\mathrm{LiClO}_{4}$ electrolyte under UV light is the same as that obtained in the dark (Fig. 7b). For such PPy films, the photo-activity of the $\mathrm{TiO}_{2}$-NTA substrate is totally hidden by the electroactivity of PPy deposit, indicating that UV illumination is strongly beneficial during electropolymerization. Moreover, it has to be noted that electrochemical deposition of PPy seems to have electrically activated the surface of $\mathrm{TiO}_{2}-\mathrm{NTA}$, since the $\mathrm{TiO}_{2}-\mathrm{NTA} / \mathrm{PPy}\left(\mathrm{ClO}_{4}\right)$ junction behaves like a conductor in the dark, in spite of the underlying $\mathrm{TiO}_{2}$-NTA that is insulating in the anodic potential range in these conditions.

A comparison between the voltammogramms obtained in SDBS (Fig 5b) and those obtained in $\mathrm{LiClO}_{4}$ (Fig $7 \mathrm{~b}$ ) shows that the shape $\mathrm{f}$ the voltammograms of the hybrid structure obtained in $\mathrm{LiClO}_{4}$ is very close to the shape observed on Pt (Fig 7c) in the same medium, whereas a clear difference between the shapes on the two substrates is observed in SDBS (fig $5 \mathrm{~b}$ and $\mathrm{b}$ ).Though the deposited polymer amount is different in the two cases, it seems that the hybrid structure formed in $\mathrm{LiClO}_{4}$ shows higher electroactivity in comparison with the structure formed in SDBS.

\subsection{Electrochemical Impedance Spectroscopy}

For a deeper insight into the electrochemical behaviour of $\mathrm{Ti} / \mathrm{TiO}_{2}-\mathrm{NTA} / \mathrm{PPy}$ junctions EIS measurements were performed in the dark in order to avoid the contribution of the charge transfer resistance related to photocurrent. The electrolyte was the supporting electrolyte used for the synthesis (aqueous SDBS or $\mathrm{LiClO}_{4}$ solutions). Nyquist diagrams were plotted in the potential range $-1 \mathrm{~V}$ to $0.5 \mathrm{~V}$ vs. SCE, by $100 \mathrm{mV}$ steps, but the results are only reported for three potential values: $-0.9 \mathrm{~V},-0.6 \mathrm{~V}$ and $-0.3 \mathrm{~V}$ vs. SCE. (see Fig. 8 and 9 for PPy films obtained in SDBS and $\mathrm{LiClO}_{4}$ solutions respectively). 


\subsubsection{EIS investigations in the dark and under UV of junctions produced in SDBS}

EIS analyses of $\mathrm{Ti} / \mathrm{TiO}_{2}-\mathrm{NTA} / \mathrm{PPy}(\mathrm{DBS})$ were performed in SDBS $(0.1 \mathrm{M})$ and the response was compared to that of a bare $\mathrm{TiO}_{2}$-NTA. The sample with a PPy film synthesized in the dark (Fig. 8, black squares) exhibits a capacitive behaviour similar to that of the pristine sample (Fig. 8, blue discs) in the whole potential range, confirming that no significant amount of PPy was deposited in the dark at the surface of the tubes. In both cases, the interface could be represented by a $R_{\text {par }}(C P E)$ circuit in series with an electrolyte resistance $R_{s}$. $R_{\text {par }}$ is the resistance in parallel with a CPE element characterized by Q (modulus) and $\mathrm{n}$ (exponent). This element was used instead of a pure capacitance, but the equivalent capacitance $\mathrm{C}$ could be easily calculated using Brug's equation [21]:

$$
\begin{aligned}
& C=(R Q)^{1 / n} / R \\
& \text { where } \mathrm{R} \text { is defined by } \quad \frac{1}{R}=\frac{1}{R_{S}}+\frac{1}{R_{p a r}}
\end{aligned}
$$

An $n$ value of about 0.95 was found in the whole potential range under study, and the capacitance value decreased when the potential increased, which is the usual behaviour for a space charge layer of an n-type semiconductor (Fig. 10a, black squares and blue discs). The

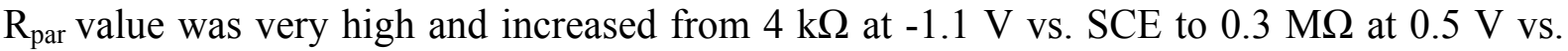
$\mathrm{SCE}$, as a consequence of progressive depletion of the space charge layer.

The situation is more complex in the presence of PPy(DBS) films electrodeposited under UV light (Fig. 8, red triangles). Between $-0.6 \mathrm{~V}$ vs. SCE and $0.2 \mathrm{~V}$ vs. SCE, they exhibit the typical shape of the EIS diagram reported in $[18,22,23]$ in the case of PPy deposited on a conducting surface, with a semi-circle in the high frequency range and a diffusion feature in the low frequency range. The capacitance associated with the HF semicircle was roughly estimated using the same equivalent circuit as for PPy electrodeposited in dark, and its evolution as a function of applied potential is also reported in Fig. 10a (red 
triangles). It appears that for the 3 samples (bare $\mathrm{TiO}_{2}-\mathrm{NTA}$, PPy(DBS) electrodeposited in dark and under UV light) this capacitance decreases in the same way with increasing potential, confirming that the semiconducting behaviour of $\mathrm{TiO}_{2}-\mathrm{NTA}$ prevails. This result is in agreement with the assumption that the surface of $\mathrm{TiO}_{2}$ is only partially recovered by PPy. Indeed the capacitance of the polymer layer is then in series with that of the semiconductor, and the capacitance response is consequently dominated by the smaller value, i.e. the $\mathrm{TiO}_{2}$ capacitance. In previous works $[4,16]$, it has been shown that this capacitance actually includes the space charge layer capacitance and the surface state capacitance which are in parallel. Nevertheless at first approximation, the experimental capacitance values were reported in a Mott Schottky representation, leading to a rough estimation of either the flat band potential value (between $0 \mathrm{~V}$ and $-0.1 \mathrm{~V}$ vs. SCE in Fig. 10b) or to the position of a localized energy state in this potential range.

The parallel resistance $\left(\mathrm{R}_{\mathrm{par}}\right)$, which equals the HF semicircle diameter is much lower in the case of PPy(DBS) electrodeposited under UV light (Fig. 11). For the deposit obtained in SDBS under UV, a minimum value for $\mathrm{R}_{\mathrm{par}}$ is observed at $-0.5 \mathrm{~V}$ vs. $\mathrm{SCE}\left(\mathrm{R}_{\mathrm{cp}}=420 \Omega\right)$, in agreement with the cathodic peak in Fig. $5 b$ due to insertion of cations into the PPy film (the difference between the potentials at the maximum of current in Fig. $5 b$ and the minimum of resistance in Fig. 11 can be due to the lack of stationarity during $\mathrm{CV}$ experiments). In the potential range positive to $-0.2 \mathrm{~V}$ vs. $\mathrm{SCE}$, the increase of the resistance is due to incomplete coverage of the surface of $\mathrm{TiO}_{2}$ by PPy. In this case the blocking behaviour of $\mathrm{TiO}_{2}$ prevails in the anodic range.

\subsubsection{EIS investigations in the dark and under $\mathrm{UV}$ of junctions produced in $\mathrm{LiClO}_{4}$}

EIS analyses were also performed in $\mathrm{LiClO}_{4}(0.1 \mathrm{M})$ in the dark and the response was compared to that of the corresponding $\mathrm{TiO}_{2}$ NTAs layer without polypyrrole. 
The Nyquist diagrams obtained for $\mathrm{Ti} / \mathrm{TiO}_{2}-\mathrm{NTA} / \mathrm{PPy}\left(\mathrm{ClO}_{4}\right)$ junctions synthesized in the dark (Fig. 9, black squares) are close to those of the bare $\mathrm{TiO}_{2}$-NTA (Fig. 9, blue discs) in the cathodic potential range, but they show a less capacitive behaviour when the potential gets more anodic than $-0.5 \mathrm{~V}$ vs. SCE, due to increasing doping of PPy when the potential increases.

The diagrams obtained for $\mathrm{TiO}_{2}-\mathrm{NTA} / \mathrm{PPy}\left(\mathrm{ClO}_{4}\right)$ synthesized under UV light (Fig. 9, red triangles) exhibit the typical EIS diagram of PPy deposited on platinum [22-24] in the whole potential range under study. For the two $\mathrm{PPy}\left(\mathrm{ClO}_{4}\right)$ samples, a simple $\mathrm{R}_{\text {par }}(\mathrm{CPE})$ circuit can no more be used to fit the experimental results, indicating that the PPy deposit has significantly modified the electrochemical behaviour at the interface. The resistance $\left(\mathrm{R}_{\mathrm{par}}\right)$ which equals the HF semicircle diameter is reported in Fig. 11 for the four samples obtained in the two media for comparison.

The physical meaning of $\mathrm{R}_{\mathrm{par}}$ is not simple and can hardly be attributed to a charge transfer resistance at the PPy/aqueous electrolytic solution interface. In [25] an accurate model has been developed in order to describe the mixed ionic /electronic conduction of a PPy membrane or of a PPy film deposited on a Pt substrate. In the present work the model is moreover complicated by the presence of a semiconducting substrate and will be the subject of a separate future work. Nevertheless for simplicity $R_{\text {par }}$ was considered here at first approximation to compare the conductivities of the four layers.

In Fig. 11, it clearly appears that hybrid structures formed in $\mathrm{LiClO}_{4}$ shows lower $\mathrm{R}_{\text {par }}$ values than the layer obtained in SDBS, confirming the higher electroactity of junctions formed in $\mathrm{LiClO}_{4}$.

In the two media, hybrid structures obtained under UV light show lower $\mathrm{R}_{\text {par }}$ values than the layer obtained in the dark in the same electrolyte. In both cases, the maximum of $R_{\text {par }}$ is located around $-0.6 \mathrm{~V}$ vs. SCE, whereas the resistance drastically decreases in the anodic 
range. This behaviour is in agreement with the oxidation current increase observed above -0.6 V vs. SCE, in the voltammogram of Fig. 7.

EIS measurements confirm that PPy deposition on $\mathrm{TiO}_{2}$-NTA is favoured by UV light which provides the photo-holes necessary for pyrrole electrochemical oxidation and electropolymerization. From our results it clearly appears that the rate of photo-electropolymerisation depends on the background electrolyte and that it is much higher in $\mathrm{LiClO}_{4}$ than in SDBS solutions. Moreover, the deposition process starts right from the first scan in $\mathrm{LiClO}_{4}$ solution, whereas an activation step seems to be necessary in SDBS solution. These observations are likely to be correlated to difference in mass transport and $\mathrm{TiO}_{2}$ surface activation in the two solutions. The initiation of electropolymerization in $\mathrm{LiClO}_{4}$ solution in the dark is less obvious to explain. Since during the synthesis, alternative anodic and cathodic scans are applied on the substrate, hydrogen insertion into the $\mathrm{TiO}_{2}$ nanotubes can be promoted, increasing progressively the doping level of the semiconductor and consequently its conductivity $[16,26-28]$. A similar explanation has been given in the case of the $\mathrm{WO}_{3} / \mathrm{PPy}$ system, for which the electroactivity in the dark in the anodic range has been attributed to $\mathrm{H}^{+}$ uptake [12]. A slight dark deposition has also been reported for the TiO2/PANI hybrid but was not clearly explained [12].

Our result is different from that of Kowalski et al. [11], who suggest that SDBS at micellar concentration favours PPy deposition in or between the tubes, even though the experimental conditions for PPy formation in their work (anodic current pulses with very high amplitude) were very different from ours.

The impedance and voltammetric results show that once the coverage rate is complete, the $\mathrm{TiO}_{2}$-polypyrrole junction behaves like a conductor in the dark, although the underlying $\mathrm{TiO}_{2}$ substrate was initially insulating in the anodic potential range. This suggests that the 
contact between $\mathrm{PPy}$ and $\mathrm{TiO}_{2}$ is ohmic. From energy level diagrams established for PPy by Miyauchi et al. [29], from reference [28], and from the estimation of the energy of the conduction band for $\mathrm{TiO}_{2}$-NTA (Fig. 10b), the electron transfer process between the oxide and the polymer is schemed in Fig. 12. It appears that the highest occupied molecular orbital (HOMO) of PPy is very close in energy to the position of the conduction band of $\mathrm{TiO}_{2}$, leading to the possibility of direct charge transfer between the two materials. The initiation of polymerisation on $\mathrm{TiO}_{2}$ under lighting, with a well adapted light source providing the holes necessary for oxidative polymerization can easily be understood. But the initiation of electropolymerisation in $\mathrm{LiClO}_{4}$ solution in the dark is less obvious to explain. and further experiments are necessary for a clear understanding.

\subsection{Characterization of $\mathrm{Ti} / \mathrm{TiO}_{2}-\mathrm{NTA} / \mathrm{PPy}$ junctions by Raman spectroscopy}

A Raman spectrum recorded in the air is reported as an example in Fig. 13. It corresponds to the sample synthesized in SDBS under illumination, after 40 scans of polarization. Similar spectra were also obtained on hybrid samples synthesized in $\mathrm{LiClO}_{4}$. According to several detailed interpretations of Raman spectra of polypyrrole films [31-33], the band at $926 \mathrm{~cm}^{-1}$ corresponds to the $\mathrm{CH}$ out-of-plane bending, the band at $987 \mathrm{~cm}^{-1}$ is assigned to the ring deformation, the band at $1050 \mathrm{~cm}^{-1}$ reflects the $\mathrm{CH}$ in-plane bending, bands at $1323 \mathrm{~cm}^{-1}$ and $1329 \mathrm{~cm}^{-1}$ are linked to the $\mathrm{C}-\mathrm{C}$ stretch and the band at $1605 \mathrm{~cm}^{-1}$ corresponds to the $\mathrm{C}=\mathrm{C}$ backbone stretch. Moreover, the spectrum does not display a peak at $1680 \mathrm{~cm}^{-1}$ usually assigned to $\mathrm{C}=\mathrm{O}$ stretching vibration, and implying overoxidation of the polymer film. The ratio between peak intensities at $926 \mathrm{~cm}^{-1}$ and $987 \mathrm{~cm}^{-1}$ is superior to the unit. This fact combined to the presence of a peak at $1605 \mathrm{~cm}^{-1}$ confirm the oxidized state of the polymer [34]. 


\section{Conclusion}

This work confirms the beneficial role of UV light illumination on the conductivity of anatase type $\mathrm{TiO}_{2}$ NTAs in the anodic potential range and therefore on the electrodeposition of polypyrrole on such substrates. This positive influence of lighting during electropolymerisation, which has already been evidenced by Janaky and co-workers[14], when PPy was deposited in sodium dodecylbenzenesulfonate, was also observed in the present work in lithium perchlorate containing aqueous electrolytic solutions, yet with a higher deposition rate in the second case.

Nevertheless two main differences have been evidenced between the two media:

- Deposition of PPy onto $\mathrm{TiO}_{2}$ NTAs in the dark is observed from the first scan in the presence of $\mathrm{LiClO}_{4}$, but is hardely detected in SDBS, in which PPy deposition must be photoinitiated..

- Once the films are formed, hybrid structures obtained in $\mathrm{LiClO}_{4}$ showed higher electroactivity than those formed in SDBS.

The overall low deposition efficiency in SDBS was mainly attributed to anion and monomer transport in and between the $\mathrm{TiO}_{2}$ NTs in micellar and therefore visqueous SDBS aqueous solutions. In the two media, once the PPy deposit was initiated, the film kept on growing mainly at the covered sites, which are likely to constitute preferential paths for charge transfer. This result, together with the energy level diagram, suggests that the contact between PPy and $\mathrm{TiO}_{2}$ is ohmic, leading to an electroactive composite 3D junction. Indeed, whatever the electrodeposition conditions are, the resulting PPy films were found to be generated in their oxidized (and not overoxidized) state, according to Raman investigations and thus able to undergo electrochemically driven redox (doping/undoping) reactions, as shown by cyclic voltammetry and electrochemical impedance spectroscopy. 


\section{Acknowledgements:}

Mr S. Borensztajn and Mrs F. Pillier are warmly acknowledged for their expertise in FEG-SEM experiments. In a similar manner, the authors would also like to thank Mr C. Bazin for the Raman spectroscopy analyses and Dr H. Fakhouri for the XRD analyses. Further, A. Desnoyers de Marbaix is acknowledged for his help related to mechanical works. 


\section{REFERENCES}

[1] J. Yan, F. Zhou, $\mathrm{TiO}_{2}$ nanotubes: Structure optimization for solar cells, Journal of Materials Chemistry, 21 (2011) 9406-9418.

[2] N.K. Allam, K. Shankar, C.A. Grimes, A General Method for the Anodic Formation of Crystalline Metal Oxide Nanotube Arrays without the Use of Thermal Annealing, Advanced Materials, 20 (2008) 3942-3946.

[3] D. Kowalski, D. Kim, P. Schmuki, TiO2 nanotubes, nanochannels and mesosponge: Selforganized formation and applications, Nano Today,8 (2013) 235-264.

[4] P. Pu, H. Cachet, E. Ngaboyamahina, E.M.M. Sutter, Relation between morphology and conductivity in $\mathrm{TiO}_{2}$ nanotube arrays: an electrochemical impedance spectrometric investigation, Journal of Solid State Electrochemistry, 17 (2013) 817-828.

[5] Z. Zhang, Y. Yuan, L. Liang, Y. Cheng, H. Xu, G. Shi, L. Jin, Preparation and photoelectrochemical properties of a hybrid electrode composed of polypyrrole encapsulated in highly ordered titanium dioxide nanotube array, Thin Solid Films, 516 (2008) 8663-8667.

[6] J. Rodriguez, H.-J. Grande, T.F. Otero, Handbook of Organic Conductive Molecules and Polymers 2 (1997).

[7] J.r. Heinze, B.A. Frontana-Uribe, S. Ludwigs, Electrochemistry of Conducting Polymers-Persistent Models and New Concepts, Chemical Reviews, 110 (2010) 4724-4771.

[8] M. Arca, M.V. Mirkin, A.J. Bard, Study of Ion Transport and Electron Transfer at Polypyrrole Films by Scanning Electrochemical Microscopy, The Journal of Physical Chemistry, 99 (1995) 5040-5050.

[9] L.T.T. Kim, C. Gabrielli, A. Pailleret, H. Perrot, Correlation between ion-exchange properties and swelling/shrinking processes in hexasulfonated calix[6]arene doped 
polypyrrole films : ac-electrogravimetry and electrochemical atomic force microscopyinvestigations, Electrochimica Acta, 56 (2011) 3516-3525.

[10] L.T.T. Kim, C. Gabrielli, A. Pailleret, H. PerrotIons/solvent exchanges and electromechanical processes in hexasulfonatedcalix[6]arene doped polypyrrole films: towards a relaxation mechanism, Electrochemical and Solid State Letters, 14 (11) (2011) F9-F11

[11] D. Kowalski, A. Tighineanu, P. Schmuki, Polymer nanowires or nanopores? Site selective filling of titania nanotubes with polypyrrole, Journal of Materials Chemistry, 21 (2011) 17909-17915.

[12] C. Janáky, N.R. de Tacconi, W. Chanmanee, K. Rajeshwar, Bringing Conjugated Polymers and Oxide Nanoarchitectures into Intimate Contact: Light-Induced Electrodeposition of Polypyrrole and Polyaniline on Nanoporous $\mathrm{WO}_{3}$ or $\mathrm{TiO}_{2}$ Nanotube Array, The Journal of Physical Chemistry C, 116 (2012) 19145-19155.

[13] M. Ouyang, R. Bai, Y. Xu, C. Zhang, C.-a. Ma, M. Wang, H.-z. Chen, Fabrication of polypyrrole/ $\mathrm{TiO}_{2}$ nanocomposite via electrochemical process and its photoconductivity, Transactions of Nonferrous Metals Society of China, 19 (2009) 1572-1577.

[14] C. Janáky, W. Chanmanee, K. Rajeshwar, Mechanistic aspects of photoelectrochemical polymerization of polypyrrole on a $\mathrm{TiO}_{2}$ nanotube array, Electrochimica Acta (2013), http://dx.doi.org/10.1016/j.electacta.2013.12.008

[15] A. G. Kontos, A. I. Kontos, D. S. Tsoukleris, V. Likodimos, J. Kunze, P. Schmuki and P. Falaras, Photo-induced effects on self-organized $\mathrm{TiO}_{2}$ nanotube arrays: the influence of surface morphology, Nanotechnology, 20 (2009) 045603.

[16] P. Pu, H. Cachet, E.M.M. Sutter, Electrochemical impedance spectroscopy to study photo - induced effects on self-organized $\mathrm{TiO}_{2}$ nanotube arrays, Electrochimica Acta, 55 (2010) 5938-5946. 
[17] K. Naoi, Y. Oura, M. Maeda, S. Nakamura, Electrochemistry of surfactant-doped polypyrrole film(I): Formation of columnar structure by electropolymerization, Journal of The Electrochemical Society, 142 (1995) 417-422.

[18] L.F.Q.P. Marchesi, F.R. Simões, L.A. Pocrifka, E.C. Pereira, Investigation of Polypyrrole Degradation Using Electrochemical Impedance Spectroscopy, The Journal of Physical Chemistry B, 115 (2011) 9570-9575.

[19] G. Dione, M.M. Dieng, J.J. Aaron, H. Cachet, C. Cachet, New composite electrodes made of polypyrrole and graphite: Construction, optimization and characterization, Journal of Power Sources, 170 (2007) 441-449.

[20] A.J. Heeger, F. Wudl, S. Barbara, Optical properties of conducting polymers, Chemical Reviews, 88 (1988) 183-200.

[21] G.J. Brug, A.L.G. van den Eeden, M. Sluyters-Rehbach, J.H. Sluyters, The analysis of electrode impedances complicated by the presence of a constant phase element, Journal of Electroanalytical Chemistry and Interfacial Electrochemistry, 176 (1984) 275-295.

[22] A. Faye, G. Dione, M.M. Dieng, J.J. Aaron, H. Cachet, C. Cachet, Usefulness of a composite electrode with a carbon surface modified by electrosynthesized polypyrrole for supercapacitor applications, Journal of Applied Electrochemistry, 40 (2010) 1925-1931.

[23] P.M. Dziewoński, M. Grzeszczuk, Towards $\mathrm{TiO}_{2}$-conducting polymer hybrid materials for lithium ion batteries, Electrochimica Acta, 55 (2010) 3336-3347.

[24] J. Kwon, Polypyrrole/titania hybrids: synthetic variation and test for the photovoltaic materials, Solar Energy Materials and Solar Cells, 83 (2004) 311-321.

[25] C. Deslouis, T.E. Moustafid, M.M. Musiani, B. Tribollet, Mixed ionic-electronic conduction of a conducting polymer film. Ac impedance study of polypyrrole, Electrochimica Acta, 41 (1996) 1343-1349. 
[26] J.M. Macak, H. Tsuchiya, A. Ghicov, K. Yasuda, R. Hahn, S. Bauer, P. Schmuki, TiO 2 nanotubes: Self-organized electrochemical formation, properties and applications, Current Opinion in Solid State and Materials Science, 11 (2007) 3-18.

[27] A. Ghicov, H. Tsuchiya, R. Hahn, J.M. Macak, A.G. Muñoz, P. Schmuki, TiO 2 nanotubes: $\mathrm{H}^{+}$insertion and strong electrochromic effects, Electrochemistry Communications, 8 (2006) 528-532.

[28] W-J Lee, M. Alhoshan, W.H. Smyrl, Titanium Dioxide Nanotube Arrays Fabricated by Anodizing Processes, Journal of The Electrochemical Society, 153 (2006) B499-B505.

[29] S. Miyauchi, Y. Goto, I. Tsubata, Y. Sorimachi, Heterojunction devices consisting of conducting polymers, Synthetic Metals, 41 (1991) 1051-1056.

[30] H. Reiss, A. Heller, The absolute potential of the standard hydrogen electrode: a new estimate, J. Phys. Chem., 89 (1985) 4207.

[31] Y. Furukawa, S. Tazawa, Y. Fujii, I. Harada, Raman spectra of polypyrrole and its 2,5${ }^{13} \mathrm{C}$-substituted and C-deuterated analogues in doped and undoped states, Synthetic Metals, 24 (1988) 329-341.

[32] K. Crowley, J. Cassidy, In situ resonance Raman spectroelectrochemistry of polypyrrole doped with dodecylbenzenesulfonate, Journal of Electroanalytical Chemistry, 547 (2003) 75 82.

[33] L. Benhaddad, M.C. Bernard, C. Deslouis, L. Makhloufi, B. Messaoudi, A. Pailleret, H. Takenouti, Chemical synthesis of hollow sea urchin like nanostructured polypyrrole particles through a core-shell redox mechanism using a $\mathrm{MnO}_{2}$ powder as oxidizing agent and sacrificial nanostructured template, Synthetic Metals, 175 (2013) 192-199.

[34] H. Nguyen Thi Le, M.C. Bernard, B. Garcia-Renaud, C. Deslouis, Raman spectroscopy analysis of polypyrrole films as protective coatings on iron, Synthetic Metals, 140 (2004) 287293. 


\begin{tabular}{|c|c|c|c|}
\hline \multirow{2}{*}{$\begin{array}{c}\text { Number of } \\
\text { electropolymerization cycles } \\
\text { under UV } \\
\text { [1 cycle: from }-0.7 \mathrm{~V} \text { to } 1 \mathrm{~V} \\
\text { VS. SCE at } 100 \mathrm{mV} / \mathrm{s} \text { ] }\end{array}$} & \multicolumn{2}{|c|}{$\begin{array}{c}\text { Characterization in SDBS [From -1.09 to } \\
0.5 \mathrm{~V} \text { VS. SCE at } 100 \mathrm{mV} / \mathrm{S} \text { ] }\end{array}$} & \multirow{2}{*}{$\begin{array}{c}\text { Uncovered } \\
\mathrm{TiO}_{2} \text {-NTA } \\
\text { surface } \\
\text { (\%) }\end{array}$} \\
\hline & $\begin{array}{c}I_{a}^{u v}-I_{a}^{\text {darkness }} \\
\text { at } 0.5 \mathrm{~V} \text { VS. } \\
\text { SCE }(\mu \mathrm{A})\end{array}$ & $\begin{array}{c}\text { Average } I_{a}^{u v}\left(\mathrm{TiO}_{2} \text { pristine }\right) \text { at } \\
0.5 \mathrm{~V} \text { VS. SCE }(\mu \mathrm{A})\end{array}$ & \\
\hline 50 & 66 & 260 & 25.4 \\
\hline 70 & 65 & 260 & 25.0 \\
\hline 100 & 67 & 260 & 25.8 \\
\hline Pristine & 260 & 260 & 100 \\
\hline
\end{tabular}

Table 1. Percentage of uncovered $\mathrm{TiO}_{2}$-NTA surface. 


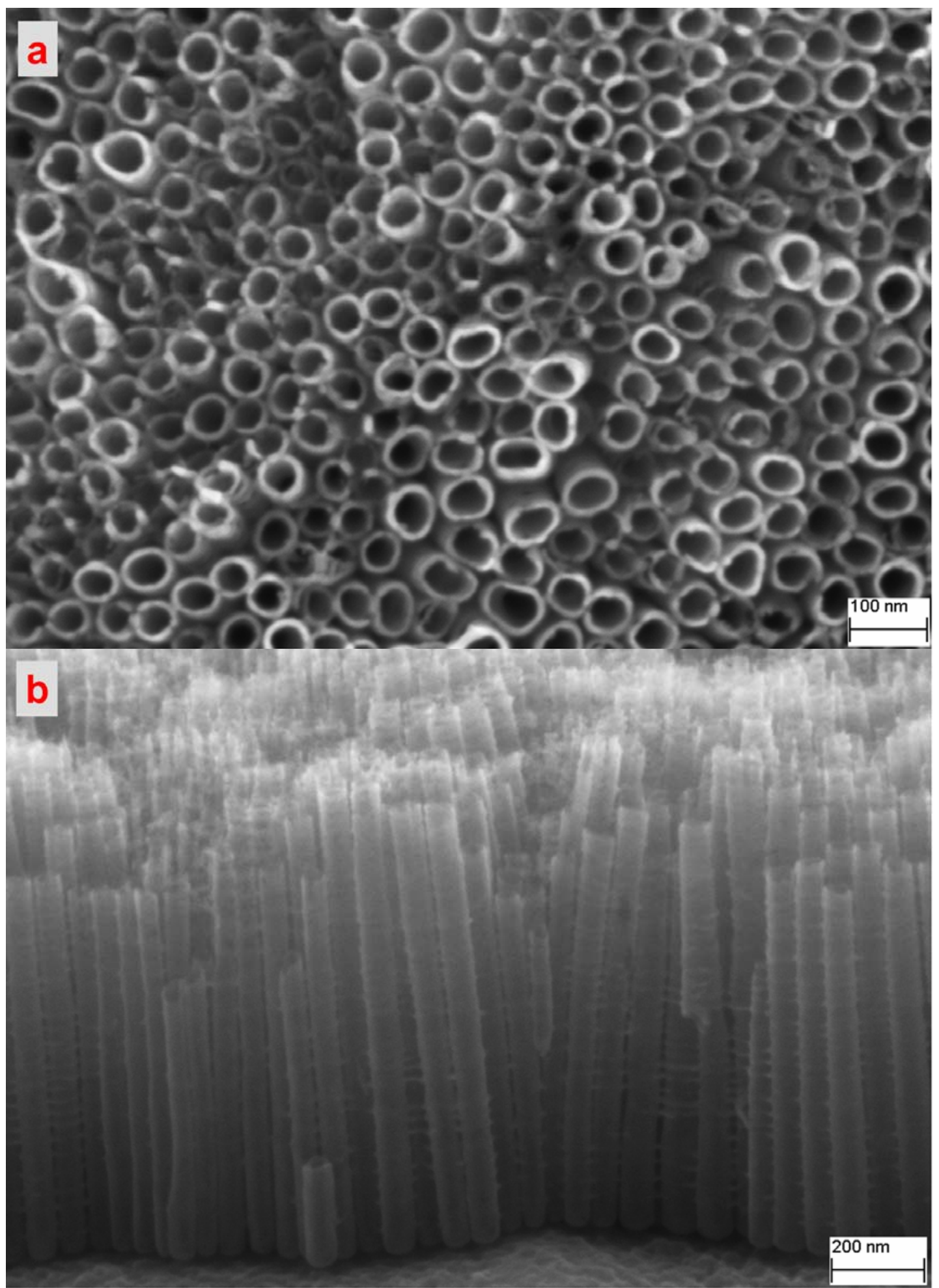

Fig. 1. FEG-SEM images of a pristine $\mathrm{TiO}_{2}$-NTA $:$ a) top view and b) side view. 


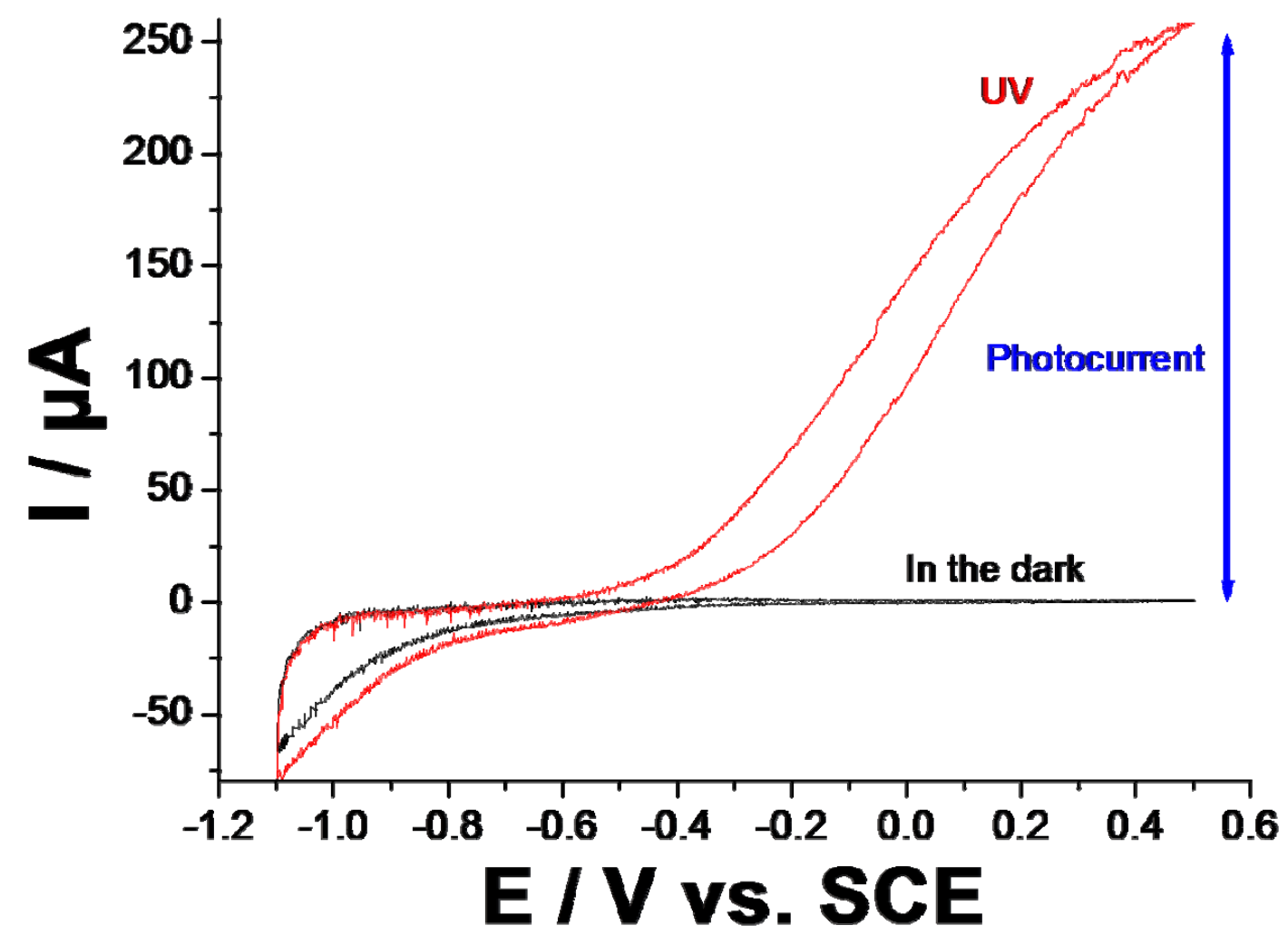

Fig. 2. Cyclic voltammetry analyses of pristine $\mathrm{TiO}_{2}-\mathrm{NTA}$ in an aqueous electrolytic solution containing SDBS $\left(0.1 \mathrm{~mol}^{-1} \mathrm{~L}^{-1}\right)$ at $10 \mathrm{mV} / \mathrm{s}$ in the dark and under UV illumination. 

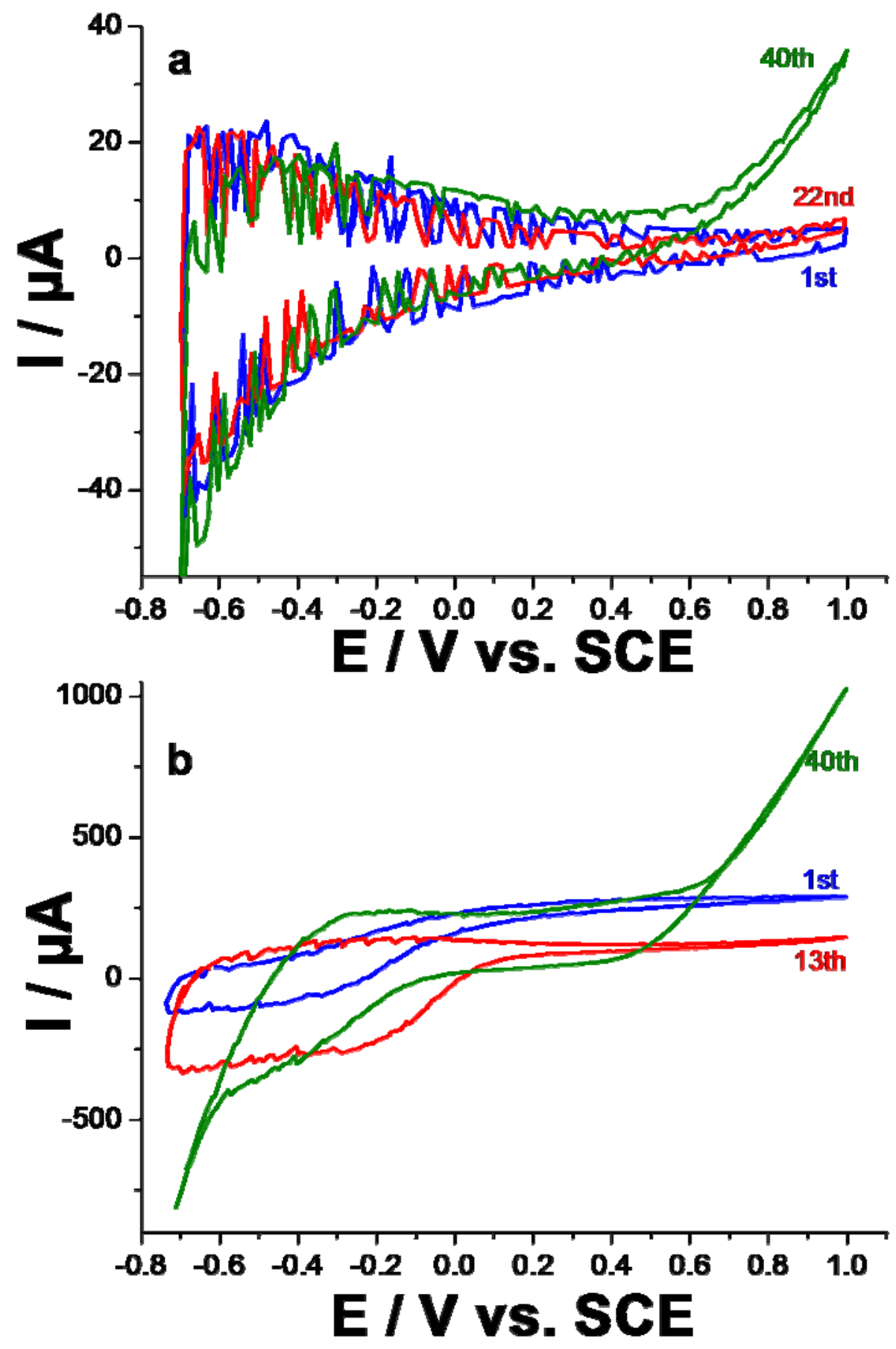

Fig. 3. Consecutive CVs (40 scans) allowing electropolymerization of pyrrole on a $\mathrm{TiO}_{2}$-NTA in an aqueous electrolytic solution containing SDBS $\left(0.1 \mathrm{~mol} . \mathrm{L}^{-1}\right)$ and Py $\left(0.1 \mathrm{~mol} . \mathrm{L}^{-1}\right)$ at $100 \mathrm{mV} / \mathrm{s}$ between $-0.7 \mathrm{~V}$ and $1 \mathrm{~V} / \mathrm{SCE}$, a) in the dark and b) under UV illumination. 

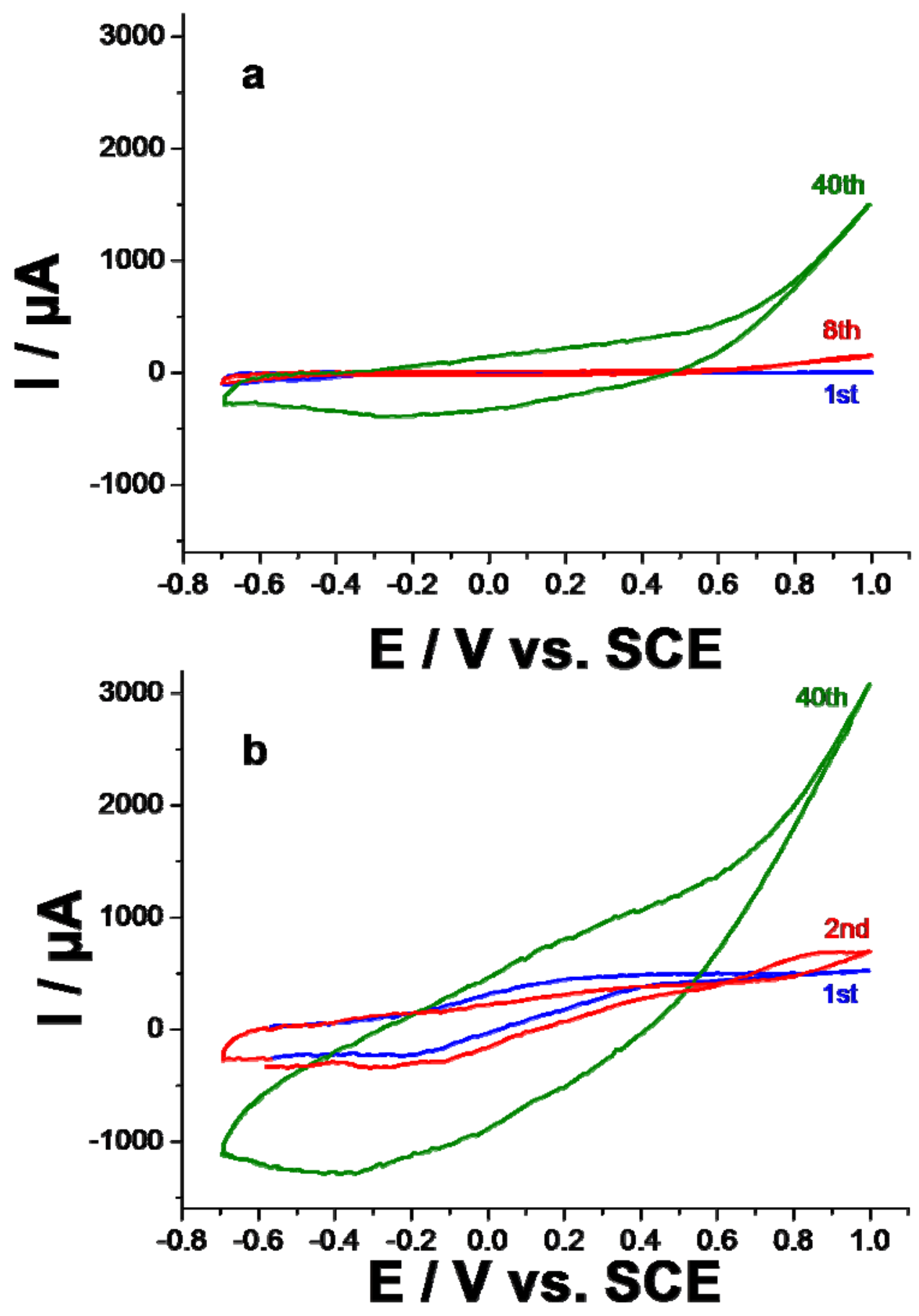

Fig. 4. Consecutive CVs (40 scans) allowing electropolymerization of pyrrole on a $\mathrm{TiO}_{2}$-NTA in an aqueous electrolytic solution containing $\mathrm{LiClO}_{4}\left(0.1 \mathrm{~mol}^{-\mathrm{L}^{-1}}\right)$ and Py $\left(0.1 \mathrm{~mol} . \mathrm{L}^{-1}\right)$ at $100 \mathrm{mV} / \mathrm{s}$ between $-0.7 \mathrm{~V}$ and $1 \mathrm{~V} / \mathrm{SCE}$ a) in the dark and b) under UV illumination. 

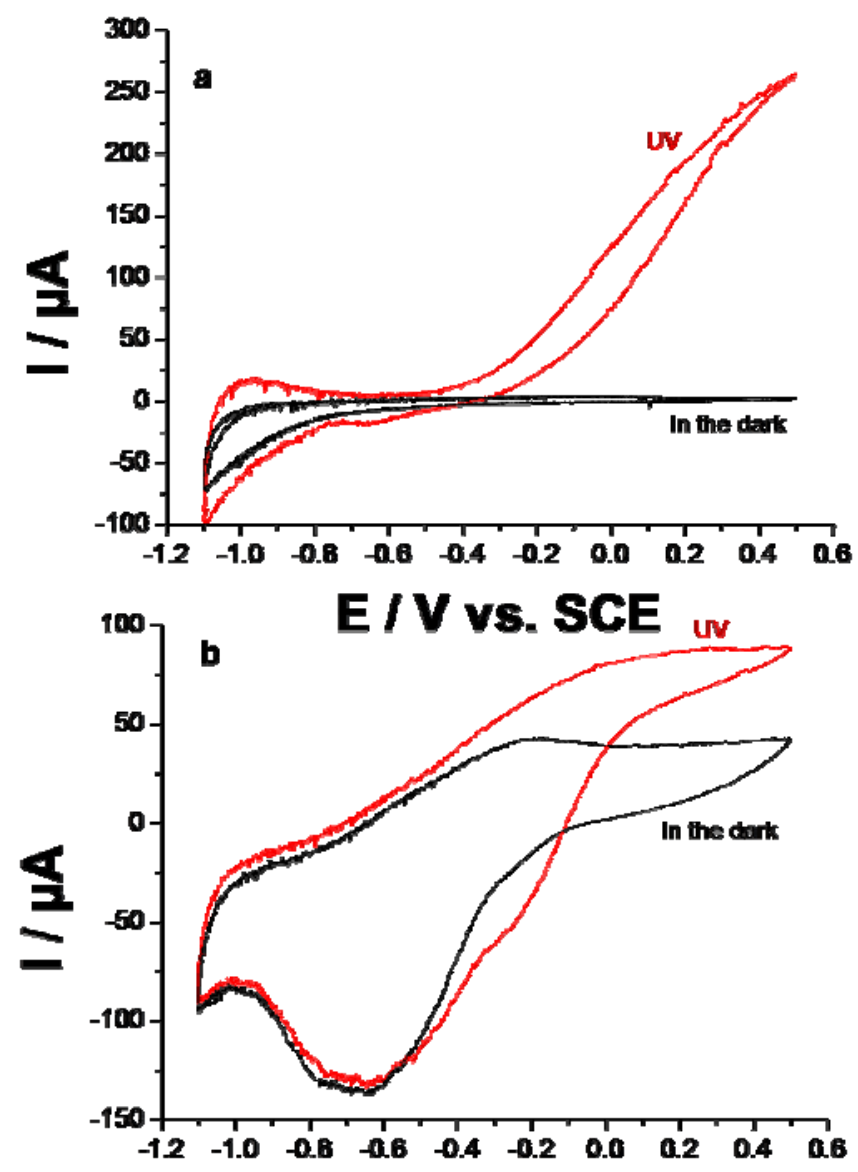

E IV vs. SCE

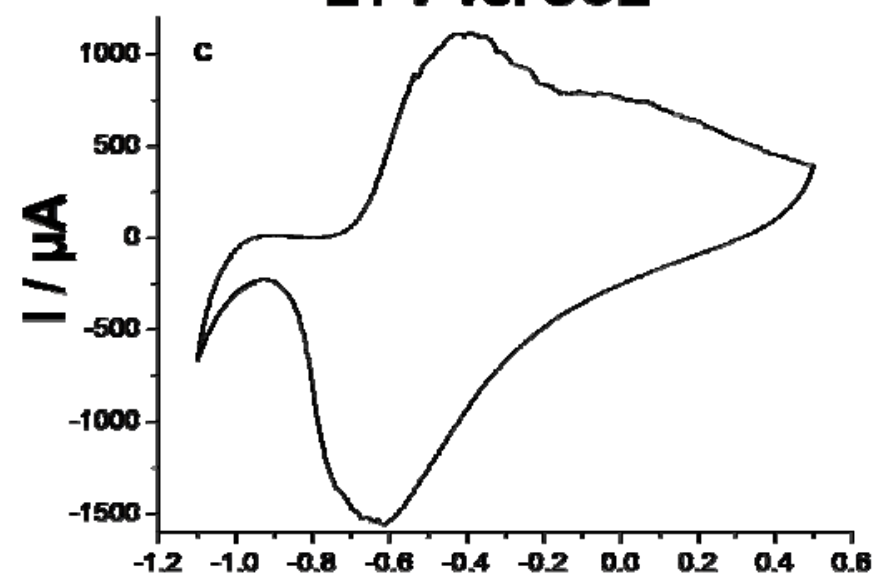

E IV vs. SCE

Fig. 5. $\mathrm{CV}$ characterization of $\mathrm{TiO}_{2}-\mathrm{NTA} / \mathrm{PPy}(\mathrm{DBS})$ junction in an electrolytic aqueous solution containing SDBS $\left(0.1 \mathrm{~mol} . \mathrm{L}^{-1}\right)$ at $10 \mathrm{mV} / \mathrm{s}$ under $\mathrm{UV}$ illumination or in the dark corresponding to electrodeposition of PPy for a) in the dark, b) under UV and c) on Pt, a metal on which electrodeposition of PPy is not influenced by illumination. 


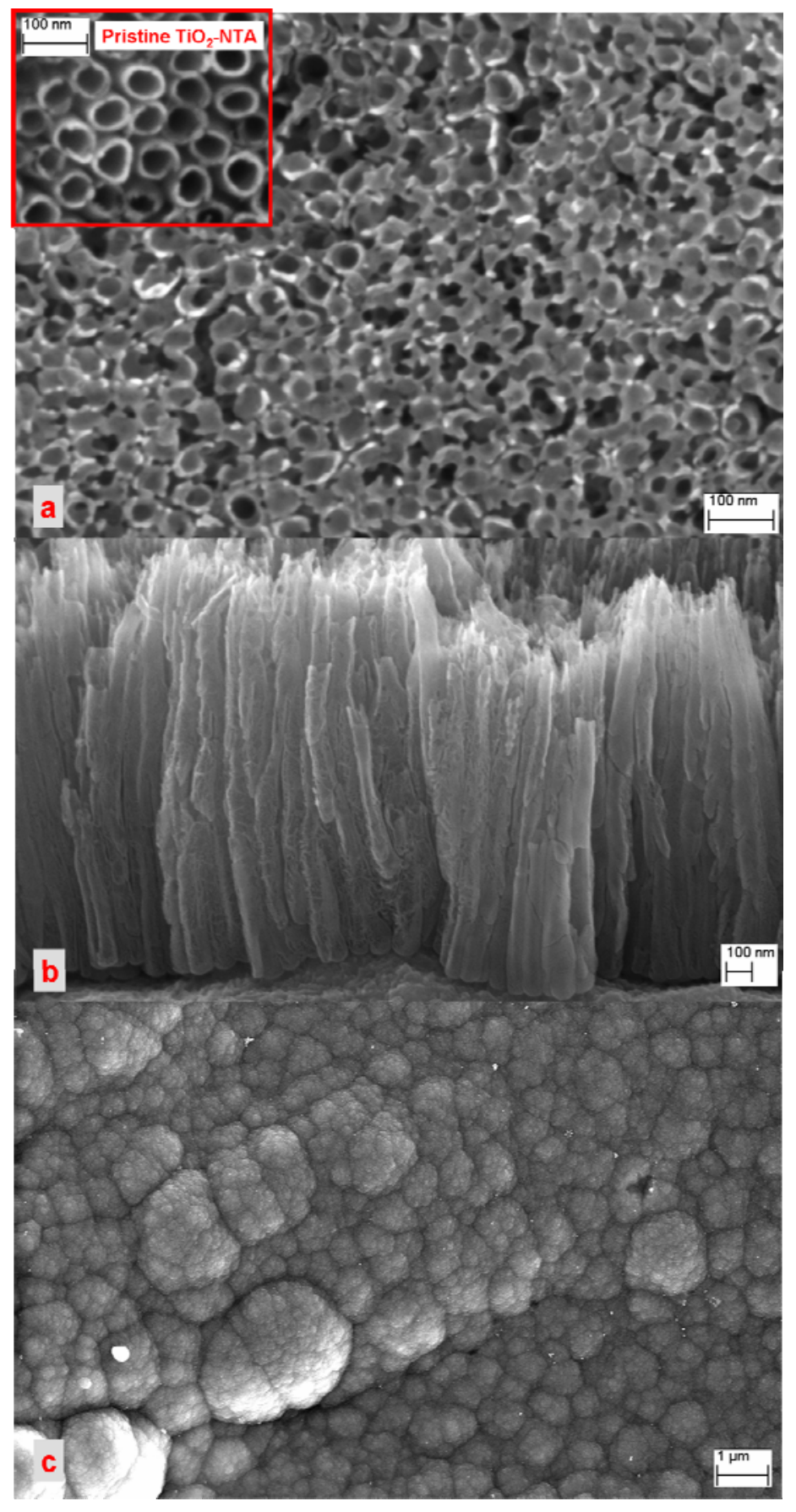

Fig. 6. FEG-SEM images of $\mathrm{TiO}_{2}$-NTA/PPy junctions obtained in SDBS, under UV and potentiodynamically between $-0.7 \mathrm{~V}$ and $1 \mathrm{~V}$ at $100 \mathrm{mV} / \mathrm{s}$ : a) Top view after 40 scans, $\mathrm{TiO}_{2}$ nanotubes are partially filled by PPy (Inset: FEG-SEM image of a pristine $\mathrm{TiO}_{2}$-NTA (b) Side view over the sample cracks after 20 scans (c) cauliflower-like structure in $\mathrm{LiClO}_{4}$ after 40 scans. 

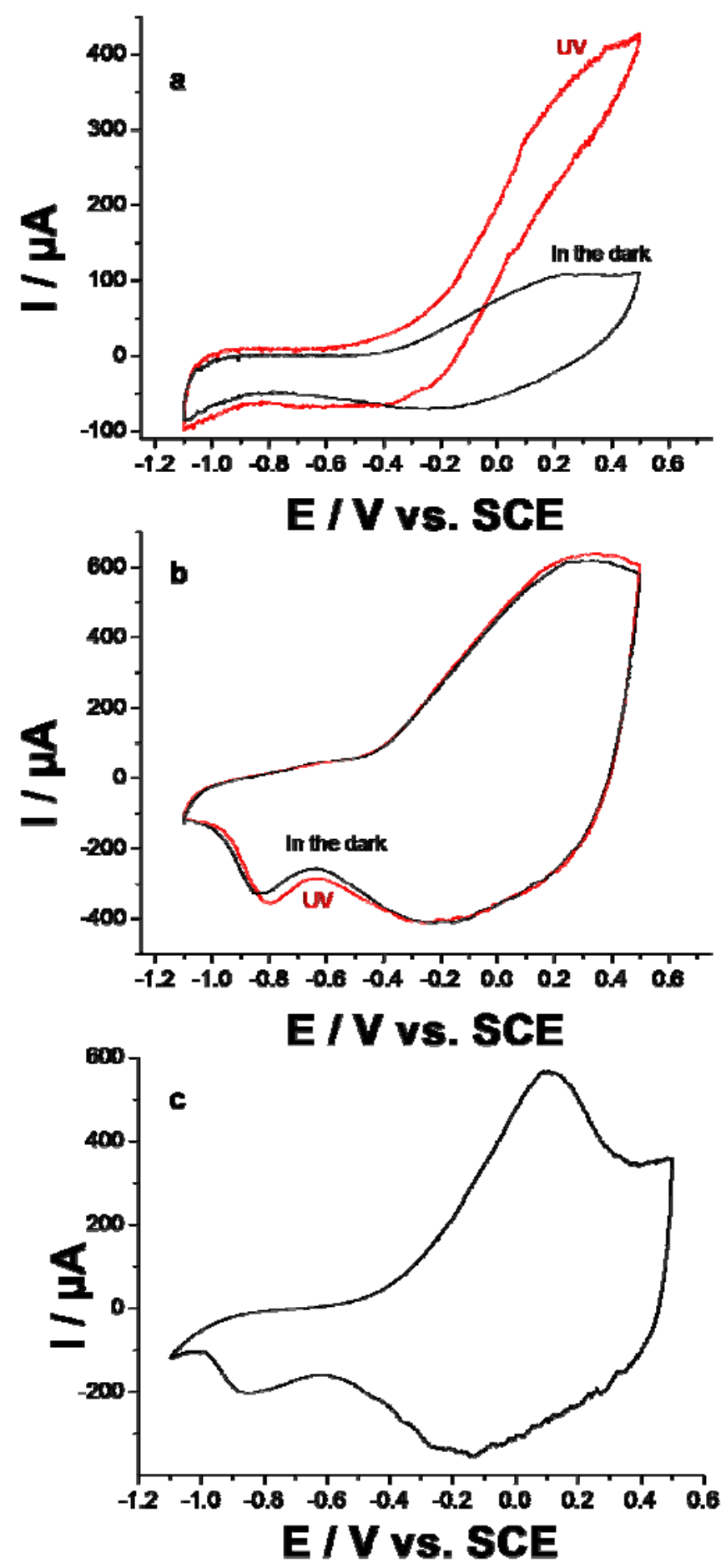

Fig. 7. CV characterization of $\mathrm{TiO}_{2}-\mathrm{NTA} / \mathrm{PPy}\left(\mathrm{ClO}_{4}\right)$ junction in an aqueous electrolytic solution containing $\mathrm{LiClO}_{4}\left(0.1 \mathrm{~mol}^{-1}\right)$ at $10 \mathrm{mV} / \mathrm{s}$ under UV illumination or in the dark corresponding to electrodeposition of PPy for a) in the dark, b) under UV illumination and c) on Pt, a metal on which electrodeposition of PPy is not influenced by illumination. 

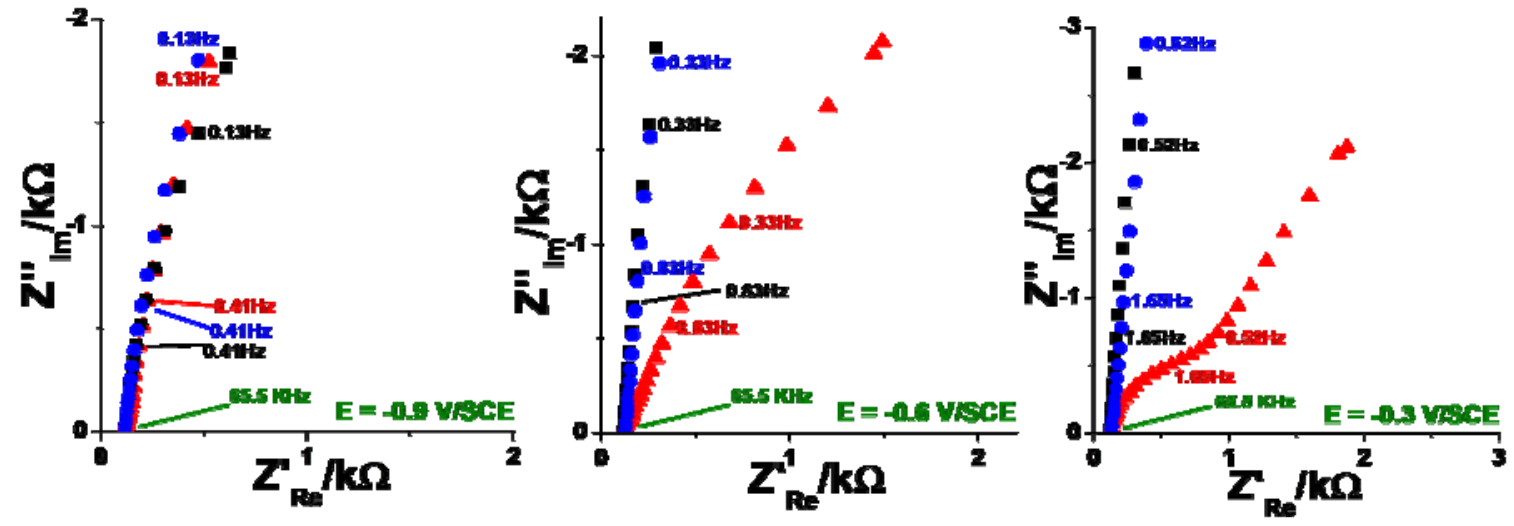

Fig. 8. Nyquist representation of EIS spectra of a $\mathrm{TiO}_{2}-\mathrm{NTA} / \mathrm{PPy}(\mathrm{DBS})$ junction synthesized in the dark (square) or under UV illumination (triangle). EIS analyses were performed in an electrolytic aqueous solution containing SDBS $\left(0.1\right.$ mol. $\left.\mathrm{L}^{-1}\right)$ in the dark. EIS spectrum corresponding to pristine $\mathrm{TiO}_{2}-\mathrm{NTA}$ is also represented (disc). 

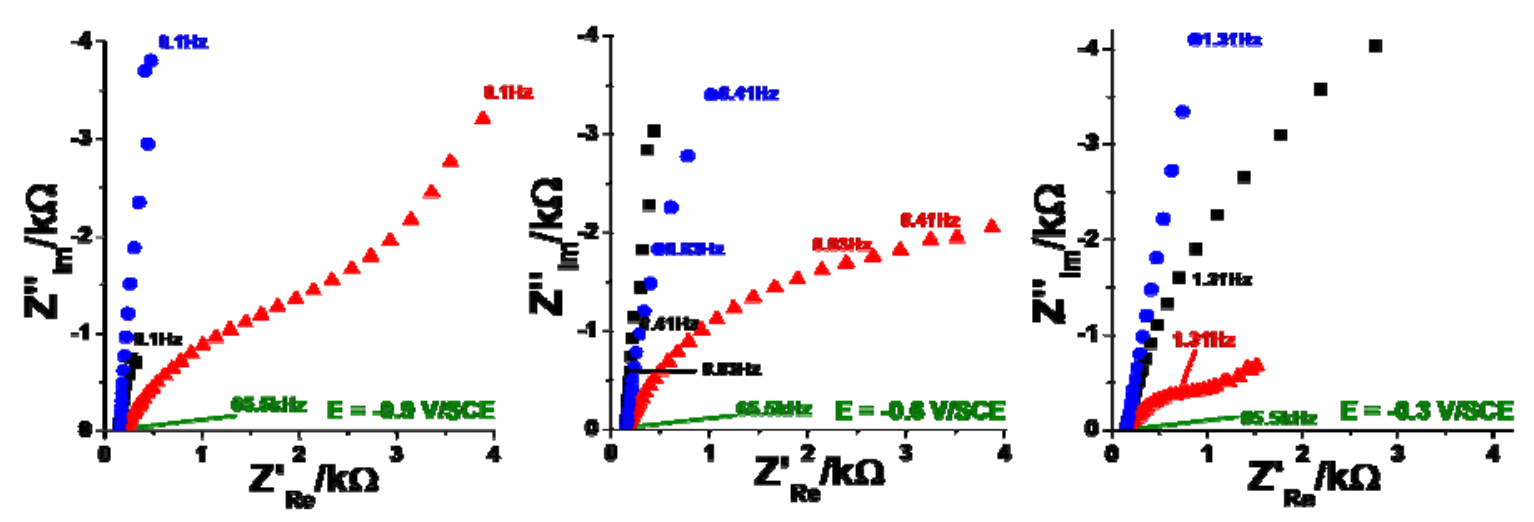

Fig. 9. Nyquist representation of EIS spectra of a $\mathrm{TiO}_{2}-\mathrm{NTA} / \mathrm{PPy}\left(\mathrm{ClO}_{4}\right)$ junction synthesized in the dark (square) or under UV illumination (triangle). EIS analyses were performed in an electrolytic aqueous solution containing $\mathrm{LiClO}_{4}$ $\left(0.1\right.$ mol. $\left.\mathrm{L}^{-1}\right)$ in the dark. EIS spectrum corresponding to pristine $\mathrm{TiO}_{2}$-NTA is also represented (disc). 

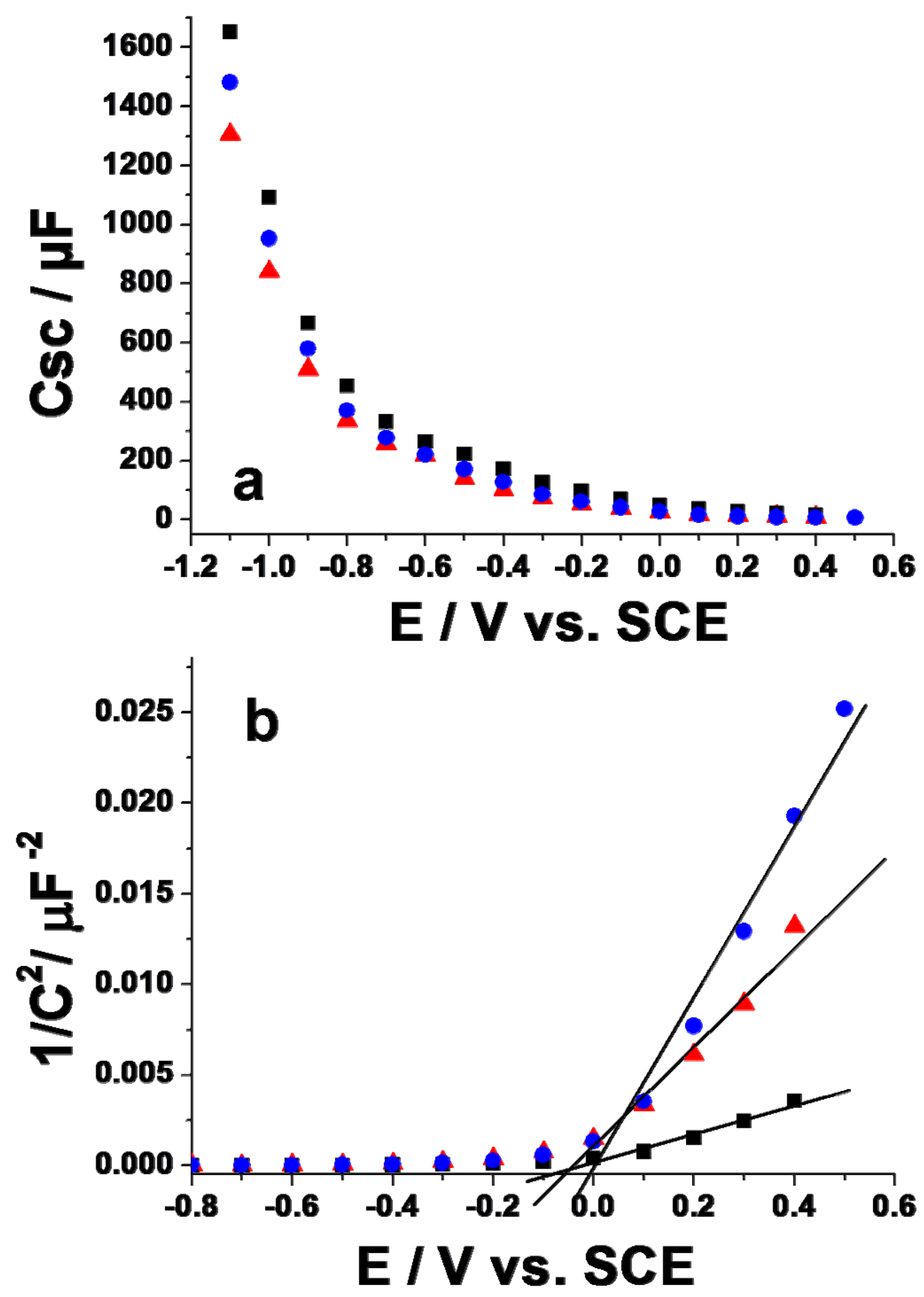

Fig. 10. a) Variation of the space charge layer capacitance as a function of applied potential in SDBS in the presence of PPy $\left(\mathrm{TiO}_{2}\right.$-NTA is measured in SDBS without PPy) b) in a Mott Schottky representation. The plots correspond to $\mathrm{TiO}_{2}$ NTA/PPy(DBS) junctions synthesized in the dark (black squares) or under UV illumination (red triangles). Evolution of the capacitance corresponding to pristine $\mathrm{TiO}_{2}$-NTA is also represented (blue discs). 


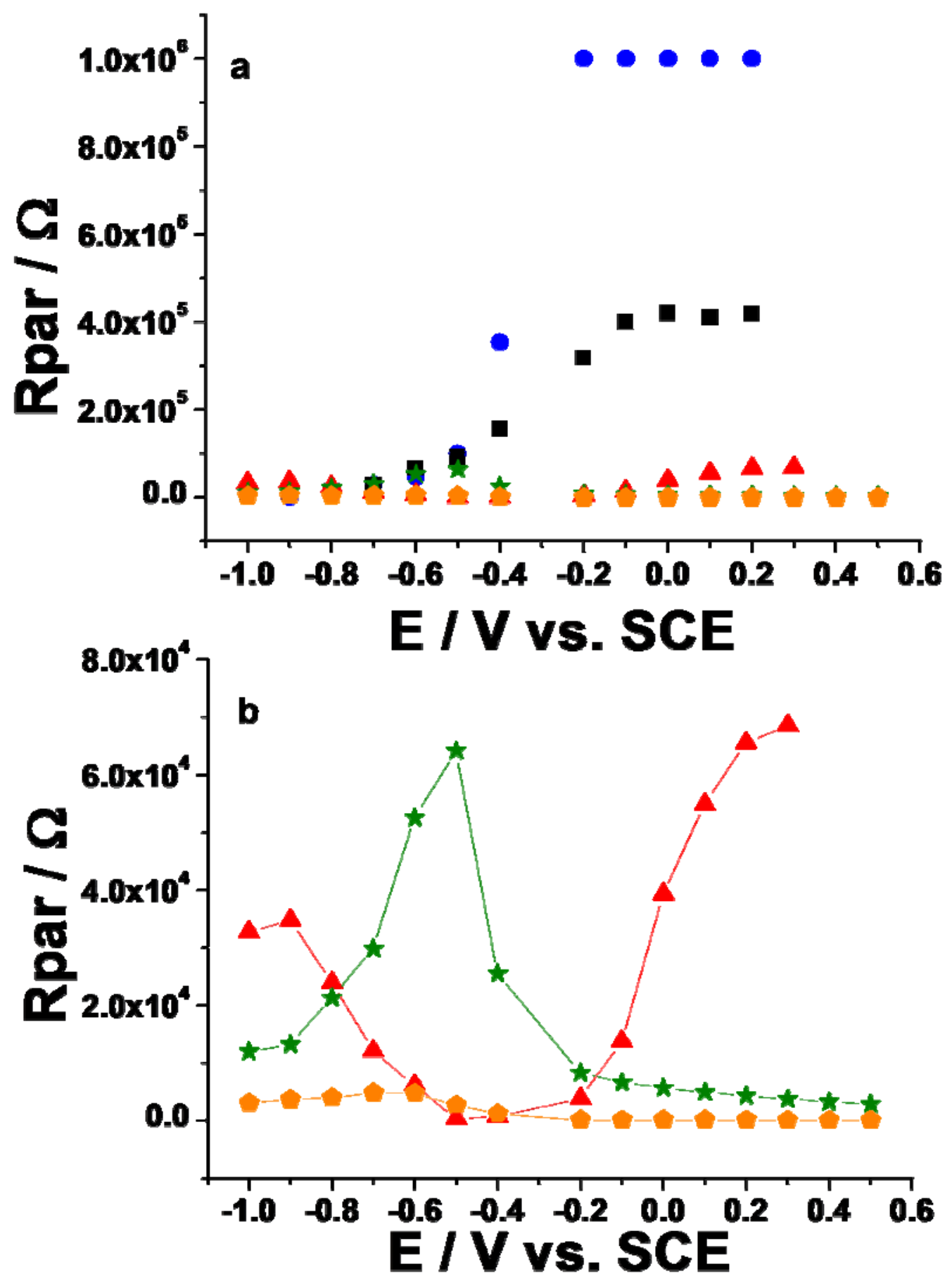

Fig. 11. Evolution of the $\mathrm{R}_{\mathrm{par}}$ value as a function of potential: a) overall view and b) Enlargement of the low resistance domain. $\mathrm{TiO}_{2}-\mathrm{NTA} / \mathrm{PPy}(\mathrm{DBS})$ junction synthesized in the dark is represented by squares. $\mathrm{TiO}_{2}-\mathrm{NTA} / \mathrm{PPy}(\mathrm{DBS})$ junction synthesized under $\mathrm{UV}$ illumination is represented by triangles. $\mathrm{TiO}_{2}$ $\mathrm{NTA} / \mathrm{PPy}\left(\mathrm{ClO}_{4}\right)$ junction synthesized in the dark is represented by stars. $\mathrm{TiO}_{2}$ NTA/PPy $\left(\mathrm{ClO}_{4}\right)$ junction synthesized under UV is represented by pentagons. Pristine $\mathrm{TiO}_{2}$-NTA is represented by discs. 


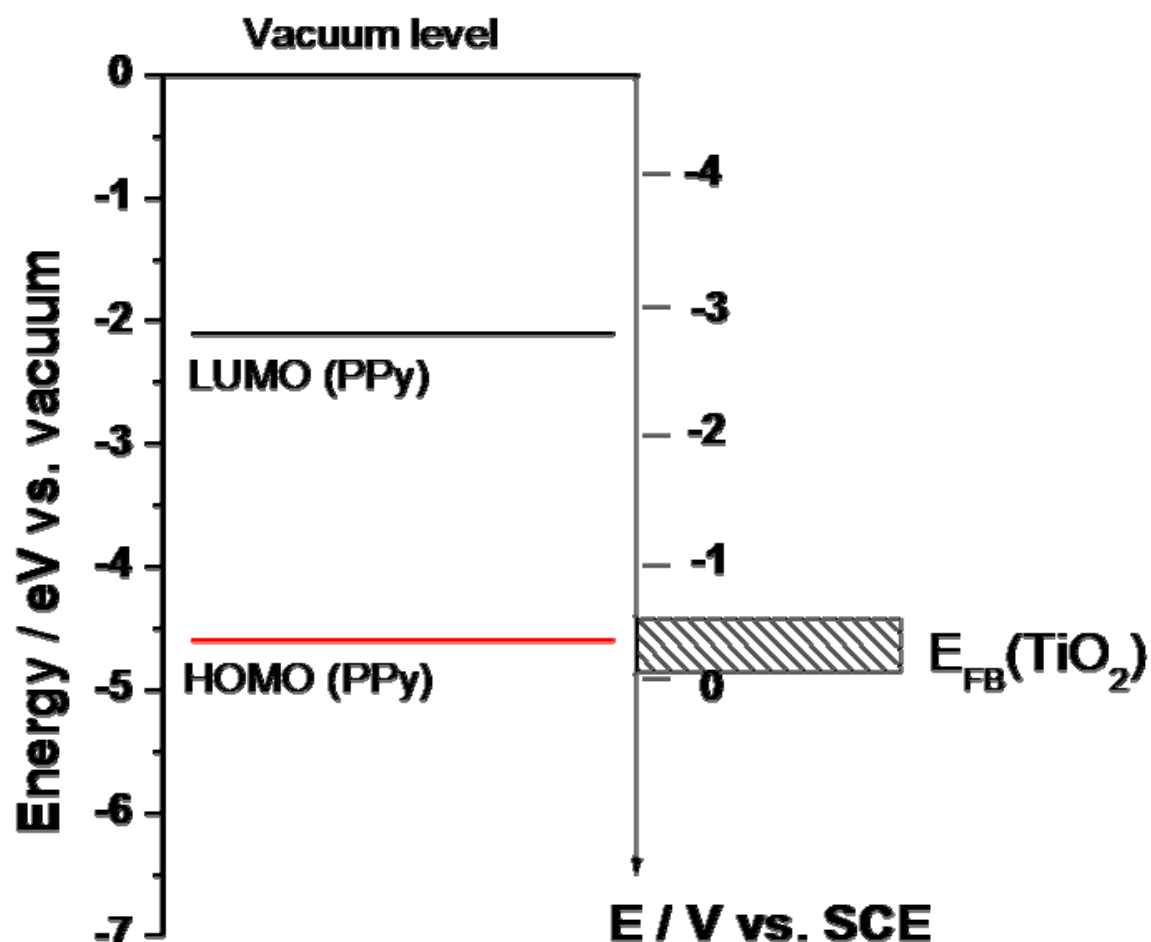

Fig. 12. Band structure of $\mathrm{PPy}^{*}$ in comparison with flat band potential of $\mathrm{TiO}_{2}$ (*From ref [27]). The conversion of the vacuum scale to the potential scale is made using $\mathrm{E}_{\mathrm{SCE}}=-4.70 \mathrm{eV}[28]$. 


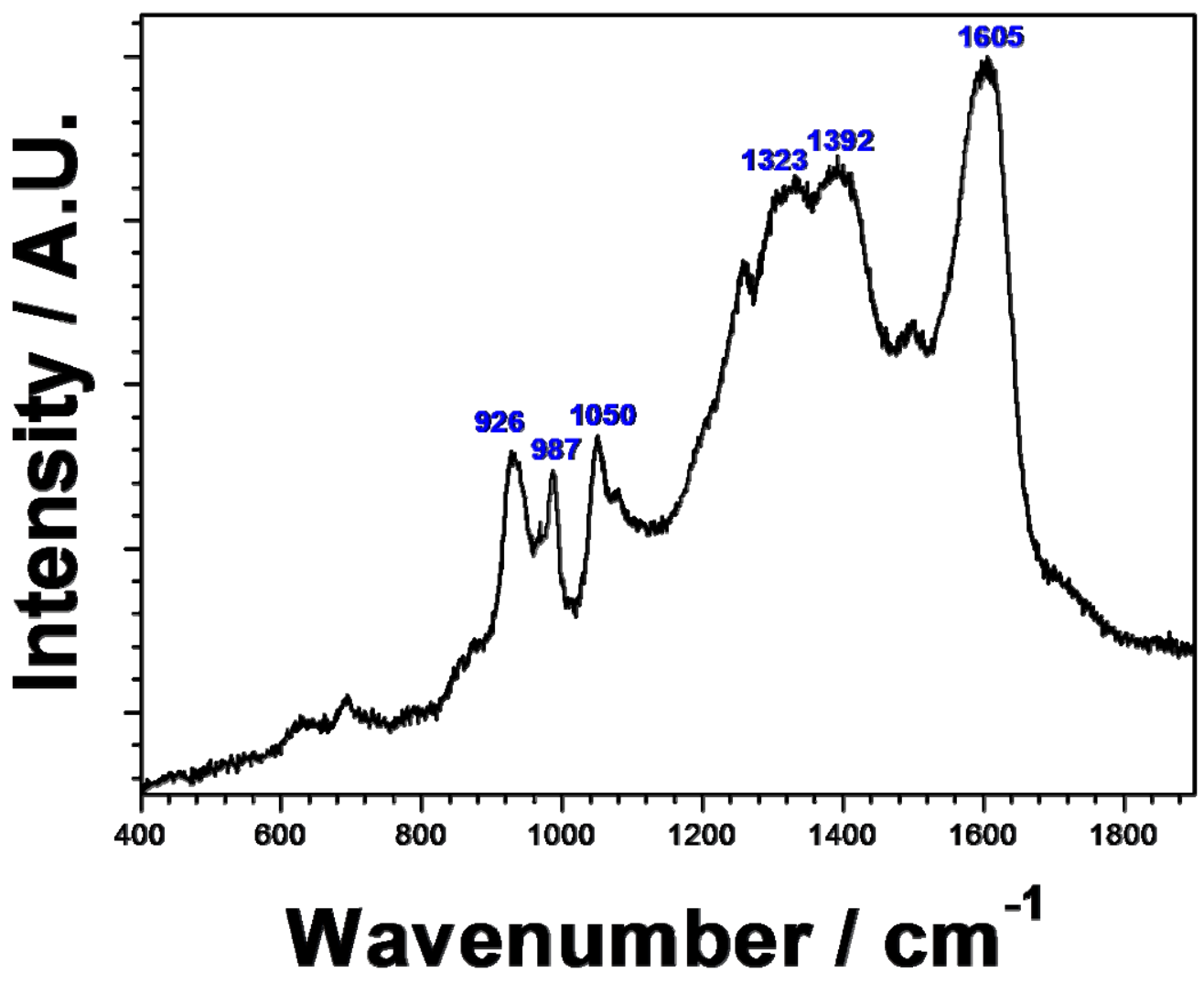

Fig. 13. Raman spectrum of a $\mathrm{TiO}_{2}-\mathrm{NTA} / \mathrm{PPy}(\mathrm{DBS})$ junction. 